NBER WORKING PAPER SERIES

\title{
THE IMPACT OF POOR HEALTH ON EDUCATION: NEW EVIDENCE USING GENETIC MARKERS
}

\author{
Weili Ding \\ Steven F. Lehrer \\ J. Niels Rosenquist \\ Janet Audrain-McGovern \\ Working Paper 12304 \\ http://www.nber.org/papers/w12304

\section{NATIONAL BUREAU OF ECONOMIC RESEARCH 1050 Massachusetts Avenue Cambridge, MA 02138} \\ June 2006
}

\begin{abstract}
We are grateful to seminar participants at the 2005 NBER Summer Institute, University of Toronto and BU/Harvard/MIT Health Economics Seminar for helpful comments and suggestions. We would also like to thank Paul Wylieto for answering our numerous questions about the data employed in the study. Lehrer wishes to thank SSHRC for research support. Rosenquist wishes to thank AHRQ for support. We are responsible for all errors. The views expressed herein are those of the author(s) and do not necessarily reflect the views of the National Bureau of Economic Research.

(C2006 by Weili Ding, Steven F. Lehrer, J. Niels Rosenquist and Janet Audrain-McGovern. All rights reserved. Short sections of text, not to exceed two paragraphs, may be quoted without explicit permission provided that full credit, including $\odot$ notice, is given to the source.
\end{abstract}


The Impact of Poor Health on Education: New Evidence Using Genetic Markers Weili Ding, Steven F. Lehrer, J. Niels Rosenquist and Janet Audrain-McGovern NBER Working Paper No. 12304

June 2006

JEL No. I2, I1

\section{$\underline{\text { ABSTRACT }}$}

This paper examines the influence of health conditions on academic performance during adolescence. To account for the endogeneity of health outcomes and their interactions with risky behaviors we exploit natural variation within a set of genetic markers across individuals. We present strong evidence that these genetic markers serve as valid instruments with good statistical properties for ADHD, depression and obesity. They help to reveal a new dynamism from poor health to lower academic achievement with substantial heterogeneity in their impacts across genders. Our investigation further exposes the considerable challenges in identifying health impacts due to the prevalence of comorbid health conditions and endogenous health behaviors.

Weili Ding

School of Policy Studies and

Department of Economics

Queen's University

Kingston, Ontario K7L 3N6

CANADA

dingw@post.queensu.ca

Steven F. Lehrer

Queen's University

School of Policy Studies

Kingston, Ontario K7L 3N6

CANADA

and NBER

lehrers@post.queensu.ca

\section{J. Niels Rosenquist}

Health Care Systems Department

Wharton School, University of Pennsylvania

Philadelphia, PA 19104

jrosenquist@partners.org

Janet Audrain-McGovern

The Transdisciplinary Tobacco Use Research

Center

University of Pennsylvania

3535 Market Street, Suite 4100

Philadelphia, PA 19104

audrain@mail.med.upenn.edu 


\section{Introduction}

The discovery of the human genome, a sequence of approximately three billion chemical "letters" that make up human DNA, the recipe of human life, is considered to be a milestone in the history of science and medicine that might have the potential to influence social science research. Consider the following question that has been investigated in the psychology, education, economics, sociology and public health literatures: Does health status affect educational outcomes? While numerous studies report that students who are obese or depressed perform poorly relative to their classmates, factors other than health could be responsible for this repeatedly observed, but potentially spurious association. To credibly claim that obesity and depression have a deleterious effect on student performance in schools one must first overcome the inherent endogeneity when considering health and education. Further, accurate measures of health are difficult to obtain and overcoming biases arising from measurement error represents a second hurdle for applied researchers.

This study overcomes these challenges by considering an instrumental variables approach, where the instruments are selected based on a growing body of evidence in several neuroscientific fields that have identified genetic markers which possess significant associations with specific diseases and health behaviors. While there has long been scientific evidence suggesting that the association between genetic factors and health is substantial, ${ }^{1}$ only recently has it been possible to collect mea-

${ }^{1}$ The importance of genetic factors to behavioral characteristics and health outcomes has been noted throughout history and the passage of physical and disease traits from parents to offspring was first explicitly studied and modeled by Gregor Mendel in the 19th century. Since this work more sophisticated studies of laboratory animals as well as comparisons between monozygotic and dizygotic twins demonstrate that behavioral characteristics and economic as well as health outcomes 
sures of genetic markers. Since genetic markers are formed at conception, they are predetermined to any outcomes including those that occur during pregnancy and at birth. Genetic markers truly fit the definition of "nature". Using this "nature filter", the health variables being instrumented will be isolated from most nurture influences or choice-based inputs such as schools parents choose for their kids, neighborhood families select to reside in, peers kids choose to associate with, among other factors that threaten the identification of education production function parameters. ${ }^{2}$ When the variations in health variables that include clinical measures of depression, ADHD and obesity are due only to the differences in genetic coding, these variations are much less likely to be correlated with the environments surrounding an individual, allowing us to recover consistent estimates of the impacts of a vector of health measures on academic performance. ${ }^{3}$ While our identification strategy relies on scientific findings, the results suggest that social environments might have to be invoked in order to understand the root of heterogeneous impacts of health on academic performance, which were in part linked to genetic inheritance. Most recently, Cutler and Glaeser (2005) compare the correlation of health behaviors between monozygotic and dizygotic twins and conclude that approximately $72 \%$ of the variation in obesity and $30 \%$ of the variation in cigarette smoking are due to genetic factors.

${ }^{2}$ This does not exclude the potential of bias from assortative matching, which we discuss in Section 5.2.2. However, the bias is likely limited as evidence from numerous studies in evolutionary biology indicates that mate choice is not based simply on genetic quality. Rather increasing evidence (surveyed in Mays and Hill, 2004) suggests that mate selection is driven predominantly by genetic diversity which is desired since it increases reproductive success.

${ }^{3}$ These impacts should be viewed as reduced form parameters and our analysis will clarify the difficulties in estimating the structural health parameter. In Section 5.2.2 we discuss issues surrounding identification that include intergenerational transmission, potential dynastic effects, assortative matching and ideal data requirements. We also discuss how using genes as instruments to identify the impacts of health offers several benefits over alternative empirical approaches, most importantly we can directly test the identifying assumptions. 
seems to place the question squarely back under the realm of social sciences.

Specifically, our empirical identification strategy is based on a large body of evidence in several fields that explain the role of specific genes in the operation of a region of the brain along the medial forebrain bundle which is responsible for reward and pleasure. ${ }^{4}$ This region is distinct from those that are known to process and retain knowledge. Evidence that different regions of the brain are activated (or correlate) with different economic decisions has been found using fMRI technology in a study of intertemporal choices (McClure, Laibson, Loewenstein and Cohen, 2004). The growing evidence in the biomedical literature that presents a significant association between certain genes in this reward system with particular health behaviors and health status such as smoking, alcohol usage, obesity, ADHD, depression and schizophrenia can not be denied.

It is worth stating explicitly that the goal of this analysis is not to report a causal link between genes and health broadly defined. While we exploit the strong neural correlations between a set of genetic markers and certain health outcomes and behaviors, we do not wish to delve into the often complicated and sometimes controversial debate on how genes affect behavior. For example, the popular press is occasionally filled with stories on the discovery of a gene that specifically codes for obesity or depression that are often quickly refuted by medical authorities.

\footnotetext{
${ }^{4}$ This evidence summarized in Section 2 suggests that possessing the genetic markers considered in our study indeed increases the sensitivity of individuals being diagnosed with certain health disorders. Second, there is no detectable evidence that the markers we consider are correlated with other genetic factors that associate with either innate ability or the development of intelligence. Note, we are not ruling out the possibility that these genes affect outcome measures of intelligenece but rather we are assuming that these genes neither directly enter or correlate with the genes directly involved in the education production process.
} 
This study extends the burgeoning literature in economics that seeks to explain the strong correlation between education and health in three directions. ${ }^{5}$ First, we present empirical evidence on a causal link running from health to academic performance. Due to biases associated with omitted variables, few studies have either empirically estimated the causal impact of health on education outcomes ${ }^{6}$ nor focused on mental health conditions despite evidence that their incidence is substantially larger than physical disorders in adolescence. ${ }^{7}$ Exceptions include Currie and Stabile (2005) which presents evidence from sibling fixed effects regressions that the negative impacts on test scores and educational attainment from a specific mental disorder, hyperactivity are quantitatively larger than those from physical health limitation. Behrman and Lavy (1998) as well as Glewwe and Jacoby (1995) use market instruments such as prices for health. They respectively find that the impact of child health on cognitive achievement varies as a function of the assumptions made concerning parental choices and that much of the impact of child health on school enrolment proxies for unobserved variables. Using an experimental approach, Kremer and Miquel (2004) overcome

${ }^{5}$ This correlation has been explained in three ways that are not necessarily mutually exclusive. The first hypothesis is that education increases health through productive or allocative efficiency (Grossman, 1972, Kenkel, 1991). The second hypothesis is the converse that poor health results in little education (Perri 1984, Currie and Hyson 1999). Finally, others have suggested that this correlation could be caused by a third unobserved variable (e.g. discount rate) that affects both education and health (Fuchs 1982).

${ }^{6}$ Grossman and Kaestner (1997) note that the majority of the empirical literature reports correlations and focuses on the effect of education on health. Strauss and Thomas (1998) present a survey of the literature on the relationship between health and income.

${ }^{7}$ Currie (2005) provides details and points out that the 1999 U.S. Surgeon General's Report on Mental Health stated "approximately one in five children and adolescents experiences the signs and symptoms of a DSM-IV disorder during the course of a year". 
the omitted variable bias problem by randomly assigning health treatments to primary schools in Kenya. Their analysis displays a mixed picture as improved health from the treatment significantly reduced school absenteeism but did not yield any gains in academic performance.

Second we take a close look at empirical measures of health. The dynamic relationships between health disorders and health behaviors revealed through our analysis clearly present a major empirical challenge. This challenge has not been clarified earlier since the majority of the literature linking health to education focuses on a single measure or proxy of an individual's health such as birth weight due to data limitations. ${ }^{8}$ Since an individuals' health consists of many physical and mental health measures including standing heart rate, blood pressure, mental clarity, etc. that constitute a rich vector which not only would be difficult to convert to a single index, but would such a single index exist it is unlikely to be well proxied by measures such as BMI or birthweight.

Third, we make a clear separation of health outcomes from health behaviors. This distinction is not apparent in earlier empirical studies which estimate equations derived from models that either exclusively treat adolescents as a "child" whose parents make all her health and education choices or indistinguishable from "adults" that make all the decisions by themselves. In contrast, we introduce a model that treats adolescents as "adolescents" since they only make a subset of all the decisions. For example, we postulate that a teenager would make decisions such as whether or not to smoke or have sex, while their parents make important human capital investment decisions such as which neighborhood to reside in, which school their child should be sent to, the type of health

${ }^{8}$ For example, see Behrman, Rosenzweig, and Taubman (1994), Currie and Hyson (1999), Behrman and Rosenzweig (2004) or Almond, Chay and Lee (2005). 
insurance to purchase and number of visits to health care providers. This hybrid in decision-making is not only more realistic but helps disentangle the impact of health status (a state variable) from health behavior (a control variable) that are treated as equivalent in the earlier literature. Since health behaviors only explain a very limited amount of the variation in health status, they are poor proxies for health status (which increases biases due to endogeneity) since they may reflect non-health preferences such as the type of peers. Further some health behaviors result from rather than cause certain particular health state, which has important policy implications. For example, adolescents may decide to smoke since the nicotine in cigarettes may help self-medicate against craving for food or some mental illnesses. Accounting for the pathway between health status and health behavior is necessary for proper interpretation of our coefficient estimates and could reveal their dynamism that has been understudied in earlier work.

Our empirical analysis reaches four major conclusions:

1) Genetic markers show a great deal of promise as a set of instrumental variables. The markers and their two by two polygenic interactions that we consider are strongly associated with each health behavior and status in the study. Moreover, statistical tests demonstrate that these instruments only affect academic performance through the health outcomes.

2) The impact of poor health outcomes on academic achievement is substantial. Depression and inattention both lead to a decrease of 0.5 GPA points on average, which is roughly a one standard deviation reduction. However, there is substantial heterogeneity in the impact of health on academic performance across gender. The academic performance of female students is strongly 
and negatively affected by poor physical and mental health outcomes. The estimated magnitudes are substantially smaller for male students and not a single poor health condition has a statistically significant impact.

3) To accurately estimate the impact of health status, it is important to account for endogenous health enhancing or health deteriorating behaviors. We find that treating the stock of lifetime smoking as exogenous leads to substantially different impacts of adverse health status on education. Cigarette smoking is endogenous and we find that accounting for this choice reduces the negative impact of depression inattention and ADHD by over $50 \%$ for the full sample and females. In addition, ignoring the endogeneity of smoking leads to obesity being positively and significantly related to achievement for males.

4) The presence of high comorbidity of health disorders is striking, thus the importance of accounting for it. Comorbidity is defined as having two or more diagnosable conditions at the same time. For example, research has suggested that between 50 to 65 percent of children with ADHD have one or more comorbid conditions such as depression (Pliszka et al., 1999). Unless the exogenous genetic or environmental factors can be clearly disentangled between these disorders, estimating the causal impact of one disorder in the absence of related health states may not provide accurate results. In our analysis, we estimate a large and significant positive impact of obesity on academic performance in males and inattention (AD) for the full sample when we do not account for the full health vector. Further, the significant impact of hyperactivity (HD) changes signs when one controls for the full vector of health states. Since many individuals suffer from more than one 
disorder, ignoring related illnesses may lead to some misleading conclusions.

The rest of the paper is organized as follows. In Section 2, we provide an overview of the scientific literature linking genes to health behaviors and health outcomes. An overview of the data we employ in this study is provided in section 3. The framework that guides our understanding of how education and health interact in adolescence is described in section 4 . We discuss the identification strategy and estimating equations in this section. Our results are presented and discussed in Section 5. A concluding section summarizes our findings and discusses directions for future research

\section{Scientific Primer on Genetic Markers}

Since it was not possible to collect data on genetic markers, empirical researchers in the social sciences traditionally chose to either ignore or assumed the unobserved heterogeneity conferred by variation in genetic inheritance is fixed over time for the same individual or across siblings or twins. Yet recent advances in fields of molecular and behavioral genetics, most notably through the decoding of the human genome (Venter et al., 2002) permits researchers to elucidate how differences in the genetic code correlate with differences in specific behaviors or outcomes across individuals. While researchers were able to identify the genetic code for a number of inherited traits and diseases such as eye color, cystic fibrosis, and Huntingdon's disease, most products of inheritance have been found to be polygenic, caused by the interaction of numerous genetic markers. The health outcomes 
and behaviors we consider are thought to be polygenic with researchers associating approximately 160 genes with obesity (Perusse et al., 2005) and 42 genes with ADHD (Comings et al., 2000). For these disorders researchers have focused their attention on genes involved in the reward pathway of the brain. This pathway is closely linked to primal drives such as feeding and sex, and has been shown to have a powerful effect on decision making among higher mammals including humans. For example, in a well-known study (Olds, 1956), rats that were given the choice of food versus stimulation of their reward system by electrodes ended up starving to death rather than lessening the stimulation of their pleasure center.

Since the reward system of the brain has been found to be closely linked to numerous human activities such as addiction much research has focused on how variation in different components of the pathway might make an individual more or less predisposed to addiction. In general, this system operates when activities such as feeding or sex are undertaken. A region of the brain known as the ventral tegmental area (VTA) is activated and neurons (brain cells) in the VTA release signaling molecules known as neurotransmitters (in this case dopamine ${ }^{9}$ ) to another area of the brain known as the nucleus accumbens (NA). These signals pass through the synapses (small gaps separating neurons) until they eventually reach the frontal cortex, where most "decisions" are made. Increases in the synapse of either neurotransmitters or receptor neurons for them allow for a much stronger signal to be sent. ${ }^{10}$ Since the response of these neurons to nicotine and other substances has been

\footnotetext{
${ }^{9}$ Dopamine has been called the "pleasure" chemical of the brain because people who are electri-
} cally stimulated in the limbic dopaminergic centers of the brain report intense feelings of well-being and sometimes orgasm.

${ }^{10}$ Certain food and drugs such as nicotine or caffeine can have an especially powerful effect on the 
shown to vary between individuals, it has been hypothesized that genetic differences could explain why different individuals report different levels of "highs" when smoking cigarettes, which is the underlying idea of having a genetic predisposition. In addition, since the VTA-NA pathway is important in regulating pleasure and, therefore, emotion, a number of behavioral traits including depression and ADHD have been linked to this pathway.

The particular genetic markers included in this study were chosen based upon a large and growing body of research showing a correlation between their variation and traits such as smoking behavior and depression, controlling for other relevant factors. These markers include the, i) Dopamine Receptor D2 locus (DRD2), ii) SLC6A3 locus (DAT), iii) Tryptophan hydroxylase locus (TPH) and iv) CYP2B6 locus (CYP). Each person inherits from each parent, a single copy known as an allele for each marker. Alleles can differ by the particular building blocks, or base pairs, that make up all DNA or the number of repeats, or base pairs in a row that repeat themselves. An individual who inherits 2 of the same (different) allele is considered to be homozygous (heterozygous) for that marker. Specifically, correlations between different allelic combinations also called polymorphisms and variation in behaviors and outcomes are studied to assess predispositions.

The DRD2 gene is believed to code for the number of D2 dopamine receptors on neurons in the brain, including those in the VTA. The D2 receptor is one of at least five physiologically distinct reward center of the brain as they mimic or potentiate the effects of neurotransmitters that occur there naturally. This process is often described as a molecular "hijacking" of the reward pathway. For example, nicotine has been shown to increase levels of synaptic dopamine by stimulating dopamine release in the VTA (Di Chiara and Imperato, 1988) and inhibiting dopamine reuptake in the reward pathway (Carr et al., 1992). 
dopamine receptors (D1-D5) found on the synaptic membranes of neurons in the brain. The DRD2A1 allele has been associated with a reduced density of dopamine receptors. ${ }^{11}$ Several researchers postulate that the reduced density of dopamine receptors explains the higher associations individuals with DRD2-A1 alleles (A1/A1 or A1/A2) have with compulsive and addictive behaviors including smoking, depression and obesity, relative to individuals with two DRD2-A2 alleles. ${ }^{12}$

The dopamine transporter (DAT) gene (SLC6A3) encodes a reuptake protein that regulates synaptic levels of dopamine in the brain. ${ }^{13}$ Variability in the length of the DAT gene is believed to positively influence levels of the reuptake protein in the brain. ${ }^{14}$ Individuals with shorter variants of the SLC6A3 gene have diminished dopamine reuptake and greater availability of synaptic dopamine. Since there is more synaptic dopamine it has been suggested that these individuals receive smaller benefits from substances that stimulate dopamine transmission.

The tryptophan hydroxylase gene (TPH) is a member of the serotonergic neurotransmission system and plays a crucial role in the regulation of mood and impulsivity. This particular gene is involved in the biosynthesis of serotonin, another neurotransmitter that operates in conjunction

${ }^{11}$ This finding was first reported in Blum et al. (1991).

${ }^{12}$ See Audrain-McGovern (2004) and Epstein et al. (2002) and the references within for evidence on these associations.

${ }^{13}$ Bannon, Granneman, and Kapatos (1995) present an overview of the SLC6A3 gene. The SLC6A3 gene has been implicated in Parkinson's disease (Seeman and Niznik (1990)), attention deficit disorder (Cook et al. (1995)), and Tourette's syndrome (Connors et al. (1996))

${ }^{14}$ The length is associated with the number of variable tandem repeats on each marker. Each repeat increases the amount of reuptake protein. The majority of individuals have SLC6A3 alleles with lengths of 9 or 10 base pairs, where the length is positively associated with levels of DAT protein. Note the SLC6A3 loci may also take the form of 7- repeat, 8-repeat, 11-repeat or 12repeat; each of which is extremely rare in both the population and our sample. 
with the brain's reward system. Serotonin activity has been linked to a number of behavioral and physical conditions including depression, appetite, and addictive behavior. ${ }^{15}$

The CYP genes as a group code for enzymes present in various body organs, primarily the liver which break down a number of drugs and toxins, including nicotine. Polymorphisms of the CYP2A6 gene in particular have been linked to across population differences to smoking, alcoholism, and response to anti-depression medications. ${ }^{16}$

Finally, different allelic combinations when interacted can potentially have powerful effects. For example, the level of endogenous synaptic dopamine depends not only on the amount of dopamine released but also on the number of receptors that dopamine can bind to (proxied by the DRD2 gene) as well as the amount of reuptake protein (proxied by the length of the SLC6A3 allele). Similarly, one could imagine that the rate of metabolism determined by the CYP2B6 gene interacts with both the TPH and DRD2 genes.

\section{Data}

This paper uses data primarily from the Georgetown Adolescent Tobacco Research (GATOR) study. GATOR is a unique longitudinal data set of adolescents that combines information from a series of 5 questionnaires given over four years of high school (1999-2003) along with the four genetic markers described in the preceding section.

\footnotetext{
${ }^{15}$ See Lucki (1998) for evidence of these associations.

${ }^{16}$ See Lerman et al. (2001, 2003) for a discussion.
} 
The study began in 1999 when researchers selected five high schools from the same county in Northern Virginia. ${ }^{17}$ The county contains over 950,000 residents and is one of the most affluent in the US with a median household income of $\$ 70,000$ in $1995 .{ }^{18}$ School administrators provided the names and mailing addresses of the complete 9th grade class roster of students for each of these schools. To recruit study participants project information packets which included an explanatory cover letter from the school principal, consent forms, and a brief demographic/response form were mailed to 2120 students' homes. ${ }^{19}$ To increase participation rates, up to three waves of mailings were sent and telephone calls were placed to encourage parents to respond. Of the $72 \%$ of the parents/guardians (1533 of 2120) who responded to the mailings, three quarters (1151) provided written consent for their adolescent to participate in the study. $99 \%$ of the 1151 adolescents who had parental consent to participate provided assent themselves. ${ }^{20}$

Biological samples were collected using buccal swabs from which DNA was extracted via standard phenol-chloroform techniques. DNA was extracted from buccal cells to avoid a selective exclusion of subjects with blood and injection phobia. Since the method to genotype varies across markers

\footnotetext{
${ }^{17} \mathrm{~A}$ total of 21 high schools exist in this county. Using data from the NCES CCD we did not find any significant differences in student demographics or standard school input measures between schools included and excluded from the sample.

${ }^{18}$ The average household income is twice that of the nation and only $8.7 \%$ of households had incomes below $\$ 25,000$ in 1995 .

${ }^{19}$ Students who the principals indicated special class placement, such as a severe learning disability or difficulty speaking and understanding the English language were excluded from the study. In total 273 students or $11 \%$ of the total population were excluded.

${ }^{20}$ See Audrain et al. (2002) for more details regarding the data collection. We compared the students who consented to the school population using data from the NCES Common Core of Data and found no significant differences in race and gender.
} 
different assays were conducted. ${ }^{21}$

In all assays, $20 \%$ of the samples were repeated for quality control. Quality control procedures included positive and negative controls with each assay and independent repeat genotyping for $20 \%$ of the results. The rate of discordance was less than 5\%, and ambiguous results were not reported. In total, full genetic information was obtained for 1032 subjects.

The GATOR study also contains basic information on demographic characteristics (i.e. race, gender, etc.), academic performance as measured by GPA (waves 3-5 only), reports on physical activity and information on smoking activity by family and residence members. In the initial survey this information was collected during mandatory grade 9 health and physical education classes. These surveys were administered by a GATOR staff member to students who provided assent. Participants received $\$ 5$ gift certificates to media stores to acknowledge their time and participation in this study.

The participants were resurveyed in the fall and spring of the 10th grade and in the spring of the 11 th and 12 th grade, for a total of five data collection waves. The rates of participation at the

${ }^{21}$ For example in conducting SLC6A3 genotyping the following assay was conducted. DNA (25 ng) was mixed with primers (20 pmol), GeneAmp PCR buffer $(10 \mathrm{mM}$ tris- $\mathrm{HCl} \mathrm{pH} \mathrm{8.3,50} \mathrm{mM} \mathrm{KCl,}$ $1.5 \mathrm{mM} \mathrm{MgCl} 2$, and 0.0001\% gelatin; Perkin Elmer, Norwalk, CT), Amplitaq DNA polymerase $(2.5 \mu$; Perkin Elmer, Norwalk, CT), and 2'-deoxynucleotides-3'-triphosphates (144 $\mu M$; Pharmacia, Piscataway, NJ) in 50- $\mu \mathrm{l}$ total volume. The reaction conditions included an initial melting step $\left(94^{0} \mathrm{C} ; 4 \mathrm{~min}\right)$ followed by 35 cycles of melting $\left(94^{0} \mathrm{C} ; 1 \mathrm{~min}\right)$, annealing $\left(65^{\circ} \mathrm{C} ; 1 \mathrm{~min}\right)$, and extending $\left(72^{0} C ; 1 \mathrm{~min}\right)$. The VNTR repeat was then determined with a $4 \%$ agarose gel electrophoresis $(3: 1$ nusieve:agarose). The authors would be happy to provide full details on the assays for the other markers by request. Note each assay was validated by confirming a polymorphic inheritance pattern in seven human family lines encompassing three generations. 
follow-ups from baseline were about $95 \%, 96 \%, 93 \%$ and $89 \%$ respectively. Similar to the initial data collection, surveys were completed during a classroom common to all students in the presence of a member of the research team. ${ }^{22}$

Students were identified on the completed survey by an identification number and during each wave a member of the research team read aloud a set of instructions, emphasizing confidentiality to promote honest responding, and encouraged questions if survey items were not clear. To minimize missing data, make-up days were scheduled for those adolescents who were absent during the regular survey administration. Further, surveys were mailed to the homes of students who had either switched schools or dropped out of school.

The GATOR data contains numerous questions on health and health behavior. Each survey contained standard epidemiological questions related to self-reported experimentation with, and current use of, cigarettes. Each participant who reported having smoked a cigarette provided additional information on both recent and lifetime cigarette use. From this information, we constructed two variables that represented whether an adolescent was currently smoking cigarettes and years of being a cigarette smoker. A current smoker was defined as having smoked a cigarette within the past month and over one hundred cigarettes over the lifetime. Using this information on being a current smoker with self-reported smoking histories we constructed a conservative measure of number of years of smoking.

\footnotetext{
${ }^{22}$ Students without parental consent completed classroom assignments during the administration of these surveys. Classroom teachers and school administrative personnel did not participate in the survey portion of the research, nor were they permitted to view participants' responses.
} 
With the exception of the survey in the fifth wave, participants completed The Center for Epidemiologic Studies-Depression Scale (CES-D), a 20-item self-report measure of depressive symptoms. Items on the CES-D are rated along a 4-point Likert scale to indicate how frequently in the past week each symptom occurred $(0=$ never or rarely; $3=$ very often $)$. The sum of these items is calculated to provide a total score where higher scores indicate a greater degree of depressive symptoms. To determine whether an individual may be depressed, we followed findings from earlier research with adolescent samples (Roberts, Lewinsohn, and Seeley, 1991) who suggest using gender and age appropriate dichotomous cutoff scores $(>24$ for female adolescents, $>22$ for male adolescents) to ascertain the presence of clinically significant levels of depressive symptoms.

The Current Symptoms Scale-Self Report Form (CSSF), a well-standardized, 18-item self-report measure were used to assess symptoms of Attention-deficit/hyperactivity disorder (ADHD) from DSM-IV (Barkley and Murphy, 1998) in the second wave survey. ${ }^{23}$ This form allows participants to rate their recent behavior regarding how often they experience symptoms of inattention (9 items) and hyperactivity-impulsivity (9 items) on a 4 -point Likert scale $(0=$ never or rarely; $3=$ very often). Typical diagnostic criteria (endorsement of at least moderate severity on at least six symptoms from either the inattention or hyperactivity-impulsivity subscale) was used to determine the likely presence or absence of clinically significant ADHD symptoms. In the final wave of the GATOR ${ }^{23}$ Barkley and Murphy (1998) describe the scoring algorithmn. The American Psychiatric Association defines ADHD as a heterogeneous neurobehavioral syndrome that begins in childhood and is applied to individuals who display developmentally inappropriate levels of attention problems or hyperactivity-impulsivity, along with impairments in functioning at home, school, or in social settings. It is important to state explicitly that we are not focusing on diagnosed cases but rather on responses to questions which are used to construct a diagnosis known only to researchers. 
survey participants provided self reports of their height and weight. These measures were used to construct body mass index and we applied standard definitions for being obese (BMI $>30) .{ }^{24}$

In total we have information on academic performance as measured by GPA (collected in waves 3-5 only), genetics, health outcomes and health behaviors for 893 study participants. Approximately $90 \%$ of these students (807 students) completed the survey in all three years. The top panel of Table 1 presents summary statistics of the time invariant characteristics of the 893 participants in our study. The sample is predominately Caucasian and the largest minority population are Asians. The percentage of African Americans and Hispanics in the student body of the schools in our sample vary between $2.07 \%$ to $12.20 \%$ and $5.54 \%$ to $19.3 \%$ respectively. The overall sample's AD and HD subscale averages fell within standard ranges (inattention mean $=5.9$; hyperactivity/impulsivity mean $=6.6)$ for adolescent samples. Over $40 \%$ of the students report that at least one of their parents was either currently smoking or was an active smoker during their childhood.

The bottom panel of Table 1 presents information on time varying controls and outcomes. Neither GPA nor percentage of students who have a household member that smokes have any substantial change in summary statistic over the three years when GPA was collected. In contrast, the number of individuals who currently smoke and have tried smoking rises rapidly during this period. The percentage of daily smokers in the 10th grade and 12th grade is similar to national averages calculated using the NELS88 (Miller, 2005). The percentage of depressed adolescent in our sample is slightly higher than the 1999 estimate of the fraction of the adolescent population being

\footnotetext{
${ }^{24}$ We examine the robusteness of our results to alternative cutoffs for obesity, ADHD and depression.
} 
clinically depressed (12.5\%) from the U.S. Department of Health and Human Services. Summary statistics on one year lagged smoking and depression are included since we use these predetermined measures in our empirical analysis. Similar to our ADHD measure, we need to use predetermined variables since one could postulate that the answers from the psychological questionnaires used to diagnose these conditions could be influenced by current academic performance or another factor which simultaneously affects responses and current academic performance (e. g. divorce).

The GATOR data also contains information on smoking patterns and smoking history within the household and across a complete set of family members. Finally, we supplemented the original data with information from other sources to improve measures of the students' neighborhood and school. $^{25}$

\section{Empirical Framework}

\subsection{The Dynamics From Health to Education}

In this section, we present a three-stage model that guides our empirical analysis. The first two stages of our model incorporate elements from three competing theories in three distinct disciplines that explain the heterogeneity in health behaviors across individuals. Economics contributes the standard model of health investment (starting with Grossman, 1972). This model postulates that individuals make inter-temporal decisions trading off immediate satisfactions for future benefits.

\footnotetext{
${ }^{25}$ Data at the school level was obtained from the CCD and neighborhood information was obtained from US census records at the zip code level.
} 
Different time discount factors and value of life could result in different health choices. Psychologists claim that the heterogeneous health behaviors arise from different environment or situational factors that individuals encounter. Natural scientists hypothesize that genetic variations in single or multiple genes are associated with health differences across the population.

Stage 1 , at the beginning of period $T\left(T_{0}\right)$, adolescents choose whether or not to (continue to) engage in a risky behavior such as smoking, drinking alcohol or using narcotic drugs given their demographics, discount rates, the value of life, genetic markers and home and school environments as well as their current health status $\left(H_{i T-1}\right)$. Adolescent $i$ at time $T_{0}$ chooses action or behavior $k$ if the immediate satisfaction it provides exceeds the aggregation of the current cost and the perceived future cost to her. The immediate satisfaction that adolescent $i$ derives from action $k$ could be affected by her current health status ${ }^{26}$ and their genetic predispositions. The immediate cost of taking action $k$ includes both pecuniary parts such as price of cigarette and non-pecuniary parts such as how difficult it is to take action $k$. For instance a teenager may face obstacles in acquiring cigarettes or narcotic drugs that can be measured as time spent. The obstacle faced are determined by neighborhood, school and family environment inputs. For example, increased parental monitoring might make cigarette smoking more costly; a drug infested neighborhood might make drug usage less difficult. The perceived future costs usually depend on the discount rates and the value of life, which may vary with current health status (healthy people are more patient in general) and genetic predispositions. Since the data contains no information on this matter, wlog

\footnotetext{
${ }^{26}$ Research has also suggested that individuals with ADHD employ nicotine to enhance cognitive function (e.g. Coger et al. (1996), Levin et al. (1996) and Pomerleau et al. (1995)).
} 
we assume a non-binding monetary budget constraint for ease of exposition. As a result adolescent $i$ 's choice of $k$ is a function of the market price for $k$ that's available to $i\left(p_{k}\right)$ and the health status at time $T_{0}\left(H_{i T-1}\right)$, given $i$ 's endowed predisposition to taking action $k$ - that is, the set of genes $\left(G^{k}\right)$ associated with $k$ and the environment variables that are included in the matrix $X_{1 i T}$.

$$
k_{i T}=k\left(X_{1 i T}, H_{i T-1, p_{k}}, G^{k}, \epsilon_{i T}^{k}\right)
$$

where $\epsilon_{i T}^{k}$ captures an independent random shock. This model can be easily generalized to treat $k$ as a vector of behaviors that are either health enhancing (i.e. proper diet and regular exercise) or health deteriorating (i.e. smoking and drinking).

Stage 2, at time $T_{1}$, altruistic parents select a level of health input $l_{i T}$ for adolescent $i$, given the teenager's observed health behaviors $K_{i T}$ (not necessarily equal to $k_{i T}$ ) at the beginning of this period and revealed health status $H_{i T-1}$, that provides the highest indirect utility for their household $V_{i T}^{l}$ :

$$
V_{i T}^{l} \equiv V_{i T}\left(X_{2 i}, C_{l T}, H_{i T-1}, K_{i T}, G_{i}^{H}\right), \text { for each } l \text { available to } i^{\prime} \text { s family }
$$

where $X_{2 i}$ are person-specific and environmental characteristics of the child $i ; C_{l T}$ is the cost of health input $l$ at time $T$ which include the cost of insurance payment and the wage-rate forgone when taking care of child $i$ 's sickness etc.; and $G_{i}^{H}$ is a vector of genetic markers that provide endowed predispositions to the current state of health status.

For empirical identification, the set of genetic markers, home and school environments that impact health outcomes are not identical to those that determine health behaviors. Given the 
history of health behaviors chosen by adolescent $i$ and the health inputs chosen by $i$ 's parents, health production functions translate these elements into a vector of health outputs as follows

$$
H_{i T}=g\left(X_{2 i T} \ldots X_{2 i 0}, k_{i T} \ldots k_{i 0}, l_{i T} \ldots l_{i 0}, G_{i}^{H}, H_{i 0,} \epsilon_{i T}^{H} \ldots \epsilon_{i 0}^{H}\right)
$$

where $X_{2 i T} \ldots X_{2 i 0}, k_{i T} \ldots k_{i 0}, l_{i T} \ldots l_{i 0}$ and $\epsilon_{i T}^{H} \ldots \epsilon_{i 0}^{H}$ are the full history of individual and environmental characteristics, health behaviors, health inputs and independent random shocks to health production respectively. Child $i$ 's initial health stock at the start of life is represented by $H_{i 0}$.

We assume here a display of single-mindedness in parental preference on child health. That is,

$$
U\left(H_{i t}^{1}, \bullet\right) \geq U\left(H_{i t}^{2}, \bullet\right) \quad \text { if } H_{i t}^{1}>H_{i t}^{2}
$$

We also assume a discrete set of health input levels (i.e. health insurance packages) all well within the budget constraint. By this, we leave out the extreme cases that parents have to choose between putting enough food on the table and paying the kid's medical and insurance bills. Since our data has no health input information, this assumption places no constraints on the estimation equations. Under these two assumptions, parents will always choose $l^{*}$ that leads to the highest possible level of health for child $i$.

Stage 3 , at the end of period $T, T_{2}$, parents choose a set of education inputs (i.e. school quality, employing tutors, etc.) based on the health status of their child. Parents select among these inputs the optimal school $j^{*}$ for child $i$ which provides the highest indirect utility for their household $V_{i j}^{*}$,

$$
V_{i j} \equiv V_{i j}\left(X_{3 i}, C_{j}, Q_{j}, A_{i T-1}, I_{i}\right), \text { for each } j \text { available to child } i
$$


where $X_{3 i}$ are observable person-specific and family characteristics of the child $i$; $C_{j}$ is the cost of attending school $j$, which include the cost if living in a good school district; $Q_{j}$ is school-specific characteristics; $A_{i T-1}$ indexes child $i$ 's measured achievement at the stage of decision making; and $I_{i}$ is child $i$ 's innate abilities. The availability of schools to a child is described by the school admission rules in the local areas where parents can commute to work daily.

Conditional on the selection of school $j$ in the third stage, the standard education production model states that child $i$ in school $j$ at time $T$ gains human capital as measured by a score on an achievement test or report card. The general conceptual model depicts this level of achievement $A_{i j T}$ to be a function of the full history of family, community, school inputs and own innate abilities. These variables interact with each other in a nontrivial, unknown way. This general model expresses current achievement over time as

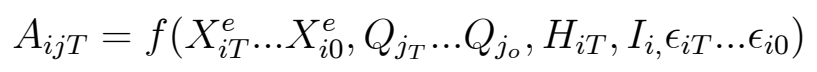

where $X_{i t}^{e}$ is a vector of community variables, individual and family characteristics in year $t, Q_{j t}$ is a vector of school characteristics, $I_{i}$ is a vector of unobserved heterogeneity including such factors as student innate abilities, parental tastes, determination, among others and $\left(\epsilon_{i T} \ldots \epsilon_{i 0}\right)$ are the full history of independent random shocks assumed to have zero mean and no serial correlation. ${ }^{27}$

There are three popular explanations put forth in the health economics literature for the observed positive relationship between health and education. The first model considers education an ${ }^{27}$ This model underlies education production function studies was first discussed in Boardman and Murnane (1979). 
investment in the future as paying large dividends the longer one lives, thus incentivizing individuals to stay healthy and live longer (Becker, 1993). The second model postulates that education is a critical component in a health production function, thus, educated individuals are better equipped to stay healthy (Grossman, 1972). The third explanation suggests that the relationship exists because both health status and education are directly related to an unobserved variable such as time discounting (Fuchs (1982)) or one's family background (Rosenzweig and Schultz, 1983). However, there's no formal economic model postulating how health enters into the education production process as an input. As a result, we hypothesize below the possible channels under which health status $\left(H_{i T}\right)$ potentially affect education.

First, it may affect the physical energy level of a child which determines the time (including classroom attendance and after school educational activities) that can be used for learning. For example, obesity has been found to be the largest determinant of absenteeism (Schwimmer et al., 2003). Second, it affects the child's mental status that may have a direct impact on academic performance. For example, obesity may cause low self esteem which leads to classroom disengagement that may reduce academic performance. Other health status such as being diagnosed with ADHD or clinical depression may directly affect a child's attention span, which adversely affects her academic outcomes. Third, a child's health status may affect the way her teachers, parents and peers treat her; this in part shapes the learning environment that she encounters. For example, obese children are often less popular among their peers and teachers. Depressed children are associated with personal distress, and if the state lasts a long time or occur repeatedly, they can lead to a 
circumscribed life with fewer friends and sources of support (Klein et al., 1997). The first two channels directly affect own health input (both physical and mental) in the education process while the latter scenario influences a child's education outcome through other inputs such as peer quality and teacher attention that is the result of a certain health status.

Ideally we would like to disentangle the effect of obesity on education (the structural parameter) from that which is due to the impact of the environment resulting from being obese. If parents, schools or peers are responding to negative health outcomes by increasing investment into other inputs this may offset the deleterious effects of poor health on achievement. Conversely the response of these individuals could move in a direction that reinforces the deleterious impact of health such as discrimination. For example, parents may decide not to invest or invest less in a child's education due to observed health status of their child. Since our data lacks information on family and school inputs as well as peers, we will obtain a combined (reduced form parameter) impact of health on education.

\subsection{The Estimating Equations}

Linearizing the achievement relationship (equation 6) yields

$$
A_{i j T}=\beta_{0 T}+\beta_{1 T} X_{i T}^{e}+\beta_{2 T} H_{i j_{T}}+\beta_{3 T} Q_{j_{T}}+\beta_{4 T} I_{i}+\left(\sum_{t=0}^{T-1} \alpha_{0 t}+\alpha_{1 t} X_{i t}^{e}+\alpha_{3 t} Q_{j_{t}}+\alpha_{4 t} I_{i}+\delta_{i t}\right)+\epsilon_{i T}
$$


where $\delta_{i t}=\alpha_{5 t} \varepsilon_{i t}$ for some coefficient $\alpha_{5 t}$. The components of equation (7) may include higher order and interaction terms. We re-express the achievement function as

$$
A_{i j T}=\beta_{0}+\beta_{1} X_{i T}+\beta_{2} H_{i T}+\beta_{3} Q_{j T}+\tilde{\epsilon}_{i T}
$$

where the vector $X$ contains individual characteristics (gender, race, residential smoking status), ${ }^{28}$ the vector $H$ is a vector of variables that captures current predetermined health measures. ${ }^{29}$ Sim- $^{\text {Sim }}$ ilarly we linearize and generate equations for both the health production function in equation (3) and the decision to engage in health behavior equation (1) as follows:

$$
\begin{aligned}
H_{i T} & =\gamma_{0}+\gamma_{1} X_{i T}+\gamma_{2} k_{j T}+\gamma_{3} G_{i}^{H}+\stackrel{\sim}{\epsilon_{i T}} \\
k_{i T} & =\delta_{0}+\delta_{1} X_{i T}+\delta_{2} H_{i T}+\delta_{3} G_{i}^{k}+\tilde{\epsilon}_{i T}^{S}
\end{aligned}
$$

Instrumental variable methods are used to estimate the above system of equations $((8)-(10))$ to generate consistent estimates of the causal impact of health on education $\left(\beta_{2}\right)$. Our identification relies on the assumption that the vectors of genetic markers that impact health behaviors $\left(G_{i}^{H}\right)$ are unrelated to unobserved components of equation (9). While there is absolutely no evidence for

\footnotetext{
${ }^{28}$ Since parents may choose to make investments in their children based on their health status, our estimates should be viewed as an upper bound of the health impact on academic performance if the investment is positively related to good health. Conversely, if the investment is negatively related to good health, our estimates provide a lower bound.

${ }^{29}$ This model is commonly used in the economics of education literature and it implicitly assumes that the effect of all previous observed and unobserved influences are zero in the current period. The empirical validity of this assumption has only recently been tested (Ding and Lehrer (2005), Todd and Wolpin (2005)) who each find support for it with school but not home inputs. This model was elected since our data lacks information on home inputs.
} 
the former assumption that the markers considered in this study have any impact on the education production process, it remains possible.

\section{Results}

\subsection{Basic Patterns in the Data}

\subsubsection{Do people win or lose the genetic lottery?}

Understanding the relationship between the genetic markers in our study provides support for our identification strategy by demonstrating that there is substantial unique variation from these markers and their interactions. Summary information on the genetic markers in our data is provided in Table 2. The DAT genotypes are classified with indicator variables for the number of 10-repeat alleles (zero, one, or two). We include indicator variables for the available AA, AC and CC genotypes of the TPH gene. Similarly, the DRD2 gene is classified as A1/A1, A1/A2 or A2/A2. Finally, we include indicator variables for the available CC, CT and TT genotypes of the CYP gene. The first column of Table 2 provides the raw number of individuals who possess each particular marker. Excluding the TPH gene, the majority of individuals in our data are homozygous for A2/A2 (of the DRD2 gene), CC (of the CYP gene) and have two ten repeat alleles of the DAT gene. For each of these genes the heterozygous combination is the next most populated and the remaining homozygous combinations of the CYP and DRD2 genes are rarest. For the TPH gene there is nearly an equal number of people who possess either the heterozygous AC or homozygous CC combination. 
The entries in the remaining columns of Table 2 indicate the number of people in each row that also possess one of the rare allele combinations of the other genes along with the conditional probability of possessing this combination. Each cell in the table is populated with at least two individuals and there does not exist any systematic relationship between the different genetic polymorphisms. ${ }^{30}$ Thus, having a rare polymorphism for one gene does not make it more likely that you would have a rare polymorphism in another gene. These results are encouraging as they do not lend support to correlations between markers of different genes.

\subsubsection{Candidate Genes for Adolescents}

To justify our four sets of genetic markers and two by their polygenic interactions to explain health behavior and status we begin by examining whether there are differences in health measures between individuals with different genetic markers. Table 3 presents information on summary measures for each genetic marker. That is, each cell contains the conditional mean, standard deviation and odds ratio of alternative health outcomes for individuals that possess a particular marker.

For each genetic marker, there exists a substantial difference in the occurrence rate of at least one of the health outcomes and behaviors. ${ }^{31}$ Individuals with the AA polymorphism of the TPH

\footnotetext{
${ }^{30}$ Statistically, to determine whether there were links between markers of different genes we conducted regressions and tests for homogeneity of odds ratios to see whether possessing a given marker increased the odds of possessing a specific marker for a different gene. We did not find any evidence indicating a systematic relationship between markers of any two of these genes.

${ }^{31}$ In addition, we conducted simple linear regressions by gene of health outcomes on discrete indicators for possessing each allele combination. The regression results are available from the authors by request. Several relationships are statistically significant and we denote statistically different odds ratios with * in the Table.
} 
gene have $50 \%$ and $20 \%$ higher propensities (relative to other TPH markers) for smoking and obesity respectively. For the CYP gene, those with the rare TT polymorphism are more than $85 \%$ more likely to be diagnosed with inattention (AD) and hyperactivity (HD), while those with the common CC marker are at least 50\% more likely to be obese. For the DRD2 gene, individuals with the common A2A2 allele are substantially less likely to be diagnosed as depressed or obese relative to the other DRD2 markers. Among the DAT gene, individuals with one 10-repeat (DAT1) independently have both higher rates of being diagnosed with ADHD and lower rates of depression. Individuals that have no 10 - repeats (DAT0) are associated with slightly higher smoking rates. These results clearly demonstrate that the four sets of genetic markers have statistically significant associations with our health measures.

\subsubsection{Health and Education Outcomes in Adolescence}

The well known positive association between good health and educational outcomes is also observed in the data. As indicate din Appendix Table 2, individuals diagnosed with ADHD, depression and obesity respectively have on average GPA scores that are $0.26,0.18$ and 0.43 lower than their counterparts. These differences are statistically significant (one sided t-tests). The raw GPA gap of individuals with ADHD or obesity relative to those not diagnosed increases between grades 10 to 12 by approximately $20 \%$. While the gap between depressed and non-depressed children does not vary through grades, cigarette smokers close their GPA gap with non-smokers from 0.58 in grade 10 to 0.49 in grade 11 and 0.37 in grade 12 . This is somewhat misleading as numerous individuals 
start smoking over time. These new smokers have substantially higher GPA scores than long-term smokers. Between grade 10 and grade 12 long-term smokers consistently have GPA scores that are approximately one half point lower relative to non-smokers.

Not only do smokers have lower GPA scores but they also have a higher propensity of being diagnosed with negative health status. Individuals with each health disorder are significantly more likely to be smokers at the $1 \%$ significance level. ${ }^{32}$ The largest gaps occur for individuals diagnosed with either inattention or ADHD whose smoking rate is over $250 \%$ higher than the remaining population (33\% of individuals with ADHD smoke versus $13 \%$ of the remaining individuals and $39 \%$ of individuals with $\mathrm{AD}$ smoke versus $12 \%$ of the remaining population). The propensity to smoke is twice as high among adolescents with hyperactivity (HD) relative to those not diagnosed with this disorder. Lastly, adolescents diagnosed as obese or depressed are associated with approximately $50 \%$ greater smoking propensities versus the remaining sample.

A major statistical challenge in accounting for these health outcomes is the presence of comorbid conditions. Comorbid conditions, or comorbidities, are conditions that happen to occur at the same time. For example, Biederman et al. (1995) report that seventy percent of adults with ADHD are treated for depression at some point in their life. Table 4 presents some summary information on the presence of comorbordities in our full sample. ${ }^{33}$ Column 1 of Table 4 displays the number of individuals (and marginal distribution) in each wave who smoke or have been diagnosed with either

\footnotetext{
${ }^{32}$ Results from one sided t-tests.

${ }^{33}$ Appendix Table 4 presents the same analysis for each gender. Recall being diagnosed with ADHD means that an individual has been diagnosed with either $\mathrm{AD}$ or HD. It also does not make a distinction between individuals with one or both disorders.
} 
$\mathrm{AD}, \mathrm{HD}, \mathrm{ADHD}$, obesity or depression. Across each row we present the number of individuals (and conditional frequency) who also engage in smoking or suffer other poor health outcomes. Not only are adolescents who are diagnosed with ADHD more likely to smoke but they also have a higher rate of being diagnosed as either clinically depressed or obese than their cohorts (one sided t-tests). This result is not unique to ADHD as we find that individuals diagnosed with any of these health disorders are significantly more likely to engage in smoking than those not diagnosed in grade 12 .

Since health disorders and risky health behaviors are more common among individuals diagnosed with one particular disorder than among the remaining population we will investigate whether estimates of the impacts of a disorder vary if we do not control for comorbidities. The majority of the literature on the impacts of health generally include only single outcome measure such as obesity, smoking or birthweight in their analysis. Estimates of the impact of health disorders may vary if there are both strong correlations between included and omitted health outcomes and if the omitted health outcomes have a significant impact on the dependent variable. Our instruments are unlikely to be unique to specific disorders as they are associated with the same region of the brain. ${ }^{34}$ Thus, even with the genetic instruments excluding significant comorbid conditions may result in estimates of the impacts of included disorder proxying for the effects of the omitted outcomes.

\footnotetext{
${ }^{34}$ Recall, from the scientific literature that these disorders are believed to be polygenic and that there is no unique depression or obesity or ADHD gene. Pharmaceutical companies are now in the process of examining the use of nicotine patches to deal with ADHD. Ritalin, which is currently prescribed to children with ADHD was originally developed as an anti-depressant.
} 


\subsection{Estimates of the Empirical Model}

Ordinary least squares estimates of equations (8) that ignore the endogeneity of health outcomes and smoking behavior are presented in the top panel of Table $5 .^{35}$ In our analysis we consider two different health vectors. The first health vector includes depression, obesity and ADHD. The results are reported in columns $1-3$. The second health vector (results reported in columns $4-6$ ) includes depression and obesity but decomposes the diagnosis of ADHD into being clinically inattentive (AD) or clinically hyperactive / impulsive (HD). Results for the full sample are presented in columns 1 and 4, for the sample of females in columns 2 and 5 and the male sample in columns 3 and 6 .

As shown in column 1 of Table 5, the impact of each health disorder in the first vector is negatively and significantly associated with academic performance for the full sample. The negative impact of obesity is approximately twice the magnitude of the other health outcomes. On average obese individuals have a GPA 0.37 points lower, an effect that is larger than that from any race or family variable. Column 2 shows that female academic performance is significantly negatively associated with obesity. Obese girls saw a point decrease in their GPA, a magnitude that is five times as large as being depressed. In addition, ADHD does not correlate with female's academic outcomes. In contrast, column 3 demonstrates that the impact of health measures were all negatively and significantly associated with GPA for boys but the coefficients do not vary across the health measures. Finally, the negative impact of the household environment variable is nearly twice as

\footnotetext{
${ }^{35}$ Due to space limitations estimates of equations (9) and (10) are available from the authors by request.
} 
large for boys than for girls.

Decomposing the impact of ADHD into its components, columns 4 to 6 of Table 5 indicate that $\mathrm{AD}$ was responsible for the negative coefficient of ADHD in column 1. For the full sample, HD is positively associated with academic performance. Column 6 shows a strong negative association between $\mathrm{AD}$ and GPA for males that is approximately $50 \%$ larger than that found in females. Similarly, the positive impact of HD is $50 \%$ larger for boys but is statistically insignificant for both genders. Interestingly Asian females performed significantly higher than their Caucasian classmates while there were no differences for Asian boys.

\subsubsection{Endogenous Health Outcomes and Health Behaviors: First-stage Estimates}

A challenge exists in selecting an appropriate subset of the markers in our data to serve as instruments. The scientific literature provides some (arguably weak) guidance as the evidence tends to be inconsistent across studies. ${ }^{36}$ We present and report results from instruments selected by forward stepwise estimation for each health outcome and behavior at the $5 \%$ level. This set was selected not only because it has good first stage properties for the full sample by design but rather because it is more parsimonious than the other instrument sets we used to verify the robustness of our findings. ${ }^{37}$

\footnotetext{
${ }^{36}$ These studies tend to use very small unrepresentative clinical samples. Since it is not possible (and probably unethical) to engage in random mutations of an individual genetic code we argue it is best to treat genetic predispositions as a form of neural correlates with health behaviors and health status.

${ }^{37}$ For robustness, we considered seven different instrument sets for the equations. One set involved the use of the complete set of the markers in our study, another set was constructed based on our reading of the neuroscientific literature up to May 2005 and the remaining five sets were constructed from stepwise estimation using alternative selection criteria.
} 
We do not vary our instrument set across race or gender so that any observed difference in terms of health effects is not the result of the selection of different instrument sets that are race or gender variant. $^{38}$

For the markers to serve as instruments they must possess two statistical properties. First, they must have a substantial correlation with the potentially endogenous health variables. Second, they must be unrelated to unobserved determinants of the achievement equation. Table 6 presents results from two specification tests that examine the statistical performance of the instruments for each health equation and sample.

In the top panel of Table 6 we present estimates of the F-statistics of the joint significance of the instruments in the first stage regressions. For each health outcome and health behavior with each sample, the instrument set is jointly statistically significant at a level above current cutoffs for weak instruments. ${ }^{39}$ Since our estimates are over-identified, we use a J-test to formally test the overidentifying restrictions. The associated p-values for these tests are presented in the bottom panel of Table 6 . The smallest of the five p-values is a reassuring 0.21 , provides little evidence against the overidentifying restrictions. In addition many of the p-values are large and exceed 0.5. However, these tests are known to have poor power properties.

\footnotetext{
${ }^{38}$ Our results (available upon request) were robust to the instrument set for the full sample and sub-sample of females. The estimates do not vary substantially either qualitatively or quantitatively. For the sub-sample of males there were some minor differences with some of the other instrument sets.

${ }^{39}$ Similarly the $\mathrm{F}$ statistics for the full set of instruments for the entire model is above current cutoffs. We report equation by equation results in Table 6 to demonstrate that the results are not driven by the instruments performing well in some health equations and not in others.
} 


\subsubsection{Endogenous Health Outcomes and Health Behaviors: Second-stage Estimates}

Two stage least squares (2SLS) results for the achievement equation (8) for the two health vectors is presented in Table 7. Column one presents results for the full sample and only depression is significantly related to academic performance. The impact of depression is approximately four times larger than the OLS estimate presented in Table 5. When ADHD is broken into components (AD and HD) both obesity and HD become statistically significant as shown in column 4. Hyperactivity and impulsiveness is positively related to academic performance. In contrast, the portion attributable to $\mathrm{AD}$ is no longer statistically significant once we correct for endogeneity.

The results for the subsample of females in columns 2 and 5 are most striking. The quantitative impact of each health behavior is substantial. Both depression and obesity lead to decreases in GPA. The impact of depression is nearly three times as large as that of obesity in health vector one. With health vector two, both depression and obesity lead to a 0.8 GPA point decrease. While the total impact of ADHD is close to zero, the separate effects of $\mathrm{AD}$ and $\mathrm{HD}$ are statistically significant. While inattention (AD) leads to lower GPA, the impact of HD is of opposite sign.

In contrast, for the subsample of males in columns 3 and 6 , health outcomes are no longer statistically significant once we correct for their endogeneity. The separate impact of obesity, depression and $\mathrm{AD}$ are statistically different across the genders. ${ }^{40}$ For each sample and health vector

${ }^{40}$ For health vector 1 , the $t$ statistic for differences in the coefficient estimates between genders is $0.502,2.499$ and 2.020 for ADHD depression and obesity respectively. For health vector 2 , the $t$ statistic for differences in the coefficient estimates between genders is $1.845,0.537,1.412$, and 1.812 for $\mathrm{AD}, \mathrm{HD}$ depression and obesity respectively. 
we checked whether health status should be treated as endogenous by testing the null hypothesis that the OLS and 2SLS estimates are equal using a Hausman-Wu test. ${ }^{41}$ We can reject the Null of exogeneity of health outcomes for each health vector with each sample at the $5 \%$ level. ${ }^{42}$

There are several additional differences between the estimates for males and females. Asian girls are associated with higher GPA scores among females. Hispanic boys have significantly lower GPA among the males. The negative impact of home smoking environment is statistically significant for both samples. The magnitude in the 2sls estimates increases relative to OLS for the boys but diminishes by approximately $40 \%$ for girls. We should emphasize that our variable indicating whether a smoker resides in the household is a proxy for family environment that we lack direct information on. Concerns regarding whether a smoker residing in the home may represent inheritability of genes from biological parents were examined. First, the raw association between biological parents having been regular smokers and the presence of a smoker in the household is $35 \%$, within the households that smoke approximately $65 \%$ of the smokers are other family members. Second, we replicated the analysis in Table 7 excluding this proxy for home environment, the magnitude as well as the

${ }^{41}$ Note, in the event of weak instruments and / or overfitting of the achievement equation the 2SLS estimates would be biased towards the OLS estimates.

${ }^{42} \mathrm{We}$ also considered the more efficient 3sls estimation of equation 8 where we accounted for the one way error component structure of $\epsilon_{i T}$ in running GLS. The 3sls results are consistent with a underlying model which treats the components of $\epsilon_{i T}$ as follows: $I_{i}$ can be viewed as a random effect that is i.i.d. across people and $\epsilon_{i T}$ is an error term which is assumed i.i.d. across grades for the same individual. There are limited efficiency gains and no substantial differences in the magnitude or significance of any of our results in this section moving from 2sls to 3sls. For completeness, 3sls results that correspond to Table 7 are presented in Appendix Table 3. The only minor change is that in the full sample with health vector 1, depression is now significant at the $10 \%$ rather the $5 \%$ level but the magnitude is virtually unchanged. 
statistical significance of the health disorders were unchanged for all three samples and two health vectors.

As indicated in Appendix Table 3, which presents comorbidities by gender, there are substantially fewer girls diagnosed with both $\mathrm{AD}$ and $\mathrm{HD}$ relative to boys. Further, there are many more depressed females particularly in the early waves. However, unlike males, girls that suffer from depression have fewer comorbid conditions.

To demonstrate the robustness of our results, Appendix Table 5 presents results for the male and female subsample that correspond to their preferred instruments sets using stepwise estimation on those subsamples. While the first stage properties for these samples are improved, a eyeball test confirms that there are no important statistical differences between these estimates and those using the instruments set constructed for the full sample with health vector 1 in Table 7. Similarly, combining the separate instrument sets for males and females and estimating the system of equations for the full sample yields no observable differences. For females with health vector 2, the positive impact of HD and negative impact of $\mathrm{AD}$ shrinks by approximately $25 \%$ with this instrument. However, the impact of depression increases by $25 \%$ with this alternative instrument set. Overall, the results continue to demonstrate that females suffer large decreases in their GPA when they have been diagnosed with $\mathrm{AD}$, depression or as obese; whereas no significant relationships exist for the males. 


\subsubsection{Discussion}

The parameter estimates we obtain are reduced form coefficients. Information on parental and teacher investment as well as peer group composition is not available to disentangle the impact of the health condition as explained by genes from that of the response from the environment to the health conditions as explained by genes. While this appears unsatisfying, this limitation is also implicitly shared by other empirical strategies used to estimate the impact of health on education which generally either treat genetics as part of a big blackbox that can be eliminated under strong assumptions or propose the use of alternative instrumental variables such as an individual's phenotype. ${ }^{43}$ The availability of genes as instrumental variables for the first time makes it crystal clear the level of difficulty in obtaining structural parameter estimates and the importance of detailed accurate information on health and education inputs. Further, structural parameters of this kind even if they could be obtained, may quickly become invalid every time a new (medical) treatment is developed that changes the occurrence rate or severity of these disorders' negative impacts.

The use of exact measures of genes permits us to enter what traditionally has been a blackbox in empirical economics. Studies that exploit variation within siblings or within twins not only assume that the set of genetic factors do not vary between pairs but implicitly the impacts of these factors and unobserved (to the analyst) family investments are constant between family members. Most unsatisfying is that one can not test the validity of these two assumptions and if they are

\footnotetext{
${ }^{43}$ Phenotype reflects the observable manifestation of a person's genotype in which the variation across individuals is due to past experiences with the environment.
} 
refuted biases could increase from differencing. ${ }^{44}$ Increasing evidence that monozygotic human twins are discordant in many physical traits and diseases is not only ascribed to environmental factors but also epigenetic modifications. ${ }^{45}$ Epigenetics refers to DNA and chromatin modifications that play a critical role in regulation of various genomic functions. Essentially a substantial degree of epigenetic variation can be generated during the mitotic divisions of a cell in the absence of any specific environmental factors. This variation which results primarily from stochastic events is either assumed the same in the sibling and twin differencing strategies or has zero impacts on outcomes.

Our 2sls estimates, however, are not assuming a constant effect on health for individuals with the same genetic markers. Drawing on Imbens and Angrist (1994), Angrist and Imbens (1995), and Angrist, Imbens and Rubin (1996) when heterogeneous response to the instrument and heterogeneous treatment effects are pervasive, the 2sls estimate can take a causal interpretation as a local average treatment effect (LATE) under two assumptions. ${ }^{46}$ This LATE parameter is simply the average causal effect on education that can be attributed to the health disorders for the subset of the population whose health disorders are induced by the chosen set of genetic markers and their

${ }^{44}$ The notion that estimates with samples of twins may increase biases is discussed in Bound and Solon (1999) and Neumark (1999) in the context of estimating the returns to education.

${ }^{45}$ For example, while $80 \%$ of the variation in schizophrenia is assumed to be heritable only half of monozygotic twin pairs in which at least one twin has the disease, share the disorder. In total, only $10 \%$ of diseases are assumed to be due strictly to heritable genetic factors. Gringas and Chen (2001) discuss the mechanisms that lead monozygotic twins to be genetically different.

${ }^{46}$ Specifically the exclusion restriction of the traditional IV literature is made stronger as the instrument is required to be entirely independent of the potential outcomes and potential treatments. Second a specific monotonicity condition on individuals' responses to shifts in the instrument is made. This condition requires those induced to change their health status by the instruments have health changes operating in only one direction. 
interactions (or, at least, a mechanism that the genetic markers reflects).

As noted, the use of genes as an instrument presents a challenge in regards to intergenerational transmission. It is well known that offspring of parents with psychological problems are more likely to develop these disorders. For example, it has been estimated that $40 \%$ of children with depressed parents experience psychiatric disorders by the age 20 (Beardslee et al., 1998). Data from the Minnesota Twin Family Study finds a weak positive association between maternal depression and offspring depression but does not find any evidence of an association between paternal depression with either maternal or offspring depression. The mechanism by which parental disorders influence offspring psychopathology has not been established and is hypothesized among other factors a combination of genes and environmental factors.

Our coefficient estimates may also capture a dynastic effect of the impact of health disorders. Without more detailed data on parental diagnoses as well as parental genes we can not separate out the portion of the impact that is uniquely brought on by the child's condition. As a result, this effect may include the impact of family environments provided by depressed parents whose depression can be explained by exactly the same set of genes and genetic interaction terms that we selcted to explain the child's depression in our study. This dynastic effect may be useful to estimate since individuals are in general not randomly assigned to families. Similarly if the assortative mating process is stable, then the dynastic effect is important to recover since kids with certain disorders will increasingly come from families that also have this disorder. It is also worth noting that there is limited evidence that individuals seek out partners with similar genetic makeup. Animal studies 
on mate choice have shown that both signals of genetic quality and genetic diversity play important roles whose relative weight varies according to the respective ranges of these characteristics in the study population. ${ }^{47}$ The pursuit of genetic diversity serves to weaken intergenerational correlations, especially on adverse health attributes.

To summarize, the genetic markers we employ in our study are predetermined to any interaction that the adolescents have with the environment, even those interactions such as pre-natal care that occur in utero and affect measures such as birth weight and APGAR scores. They possess strong correlations with certain health disorders and health outcomes. At present there is no detectable evidence that they are correlated with genetic factors that associate with inputs to either innate ability or the development of intelligence. We are not ruling out the possibility that the genes affect the acquisition of intelligence but rather we are assuming that these genes neither directly enter the education production process nor are correlated with genes involved in production of these education outcomes. The assumptions underlying these markers for identification are supported by statistical tests. Not only can these assumptions be tested but we argue that this strategy imposes substantially weaker assumptions on the relationship between nature, nurture and adolescent outcomes than other empirical strategies used in the literature. Despite these advances substantially richer data would be needed to recover the structural parameter.

\footnotetext{
${ }^{47}$ Roberts and Gosling (2003) use experiments with rodents to reach this conclusion and note that genetic diversity is desired since it increases reproductive success.
} 


\subsection{Accounting for Endogenous Cigarette Smoking Matters}

\subsubsection{Are Smoking Patterns Different Between the Sexes?}

Our analysis indicates that a substantial gap exists between the genders in the impacts of health disorders on academic achievement. One potential candidate that can account for this gender difference is smoking patterns. A strength of our data is that we have detailed information on the smoking behavior of each individual throughout adolescence. Between the sexes simple t-tests suggest that there are no systematic differences in tobacco consumption as measured in current smoking and year smoked. However, boys diagnosed with either depression, ADHD, AD, or HD smoked cigarettes with significantly more tar and nicotine content than girls diagnosed with the same disorder. ${ }^{48}$ Males with mental disorders may use the nicotine in the cigarettes to self-medicate against these disorders since nicotine is well known to have a positive effect on attention and indirect effects on the dopaminergic system, potentially reducing symptoms of ADHD and depression. ${ }^{49}$ This is consistent with the hypothesis that for individuals with limited attention spans there is an immediate academic benefit or compensation from cigarette smoking. ${ }^{50}$

While it is unlikely that only males would self-medicate with tobacco, a recent survey in the

\footnotetext{
${ }^{48}$ Simple linear regressions controlling for school effects and demographic variables confirm this observation.

${ }^{49}$ Conners et al., (1996) present research that suggests nicotine does indeed enhance attention function in adults with ADHD.

${ }^{50}$ Smoking differs from other health behaviors such as drug or alcohol use as it is not known to impair judgment and the detrimental health impacts come much later in life relative to drug use, thus appears to be less damaging in the present. Tobacco does not alter consciousness and many smokers claim that by smoking cigarettes they relieve symptoms associated with a variety of health disorders.
} 
psychiatric literature (Perkins et al. 1999) concludes that gender differences in the motivation for tobacco consumption and maintenance exist in both human and animal populations. This finding in combination with evidence that females are less sensitive to the effects of nicotine is interpreted in the survey as supporting the hypothesis that females are less likely to self-medicate with tobacco. If males are more able or inclined to take advantage of the immediate compensating benefits from smoking this may explain the difference in the impacts of the health disorders.

To investigate whether smoking patterns do indeed have different relationships with diagnosed health disorders between the genders we present OLS and 2SLS estimates of the impacts of smoking on each health outcomes for each sample and health vector in Appendix Table 6. Whereas smoking is positively associated with each health outcome when treated as exogenous (in the bottom panel), the 2sls estimates present different patterns. Smoking is positively related to ADHD and negatively related to obesity once we account for endogeneity as reported in column 1. Further, boys who smoke are significantly less likely to be diagnosed with ADHD; particularly HD. In contrast, females who smoke are less likely to be obese or be diagnosed with depression although neither impact is statistically significant at conventional levels. These gender differences add a further layer of complexity and support the possibility that smoking patterns account for some of the gap in the impacts of health disorders on education between the genders. We next examine the sensitivity of our results of treating smoking as a state as opposed to a control variable. 


\subsubsection{Are Smoking Decisions Exogenous?}

With genetic markers as instruments we can investigate the degree to which smoking is a choice variable. Past research has suggested that smoking could proxy for an individuals' discount rate in the economics literature. Several studies using this strategy have implicitly assumed that smoking does not reflect a choice. ${ }^{51}$

Treating cigarette smoking as an exogenous input to health outcomes presents striking changes to our results. Table 8 presents 2SLS estimates of equations (8) and (9) which assume this choice is exogenous. Notice that the magnitude of all health outcomes in Table 8 increases markedly from those presented in Table 7, where smoking was treated endogenous. Most surprising is that by treating smoking as an exogenous behavior, the estimates on the impact of depression, HD and obesity become statistically significant for males. The results suggest that being obese leads boys to score 0.8 points higher on their GPA. For the full sample and subsample of girls, the estimated impact of depression nearly doubles in magnitude. In addition, ADHD becomes statistically significant for the full sample. Finally, the estimates on AD and HD for girls become implausibly large but continue to offset one another. The implausible magnitude of these coefficients are a result of both limited independent variation to separately identify impacts and the use of smoking as an invalid exclusion restriction.

\footnotetext{
${ }^{51}$ This idea is due to Farrell and Fuchs (1982) and subsequent studies such as Evans and Montgomery (1994) have tried to use smoking as an instrument for education in wage equations. Hammermesh (2000) argues that smoking behavior is a measure of family background and is unlikely to be a valid instrument for education.
} 
We conducted a Hausman test of each health status equation for each vector in Table 8 by comparing it to the corresponding equation in Table 7. We can reject the Null of exogeneity for years of cigarette smoking, suggesting that smoking is indeed a choice variable. Our investigation into the endogeneity of smoking shows that despite the use of genes as instruments for the health outcomes, the different ways of accounting for the smoking decision leads to very different results. This could result from the fact that genes associated with smoking tendency are also associated with health disorders as well as smoking directly impacting health disorders. By either ignoring smoking decisions or treating smoking decisions as exogenous the exclusion restriction assumption of the genetic instrument is violated since individuals with these disorders are more likely to smoke.

\subsection{Accounting for Comorbid Health Outcomes Matters}

We now consider what, if any, effect it would have on our estimates if we followed the usual practice of ignoring comorbid conditions and only including one health outcome at a time. The results from 2SLS of achievement equations that include only one health variable are presented in Table 9. Each entry refers to the point estimate of that health behavior from a system of equation which includes the achievement equation and that health behavior or status alone.

Examining results from separate regressions using the full sample, we would conclude that inattention is positively and HD negatively related to GPA, which is the opposite of the pattern reported in Table 7 . The results for the subsample of boys completely change when comorbid conditions are omitted. Obesity, AD and HD are all positively related to academic performance 
and the magnitude of the impact for obesity is extremely large. Similarly, for the full sample and subsample of girls the impact of depression is approximately $40 \%$ larger as it may be capturing a portion of the negative impact of obesity or ADHD. Taken together, the results of Table 8 and Table 9 illustrate the need to account for a greater set of health outcomes and endogenous behaviors in any analysis. Even with exogenous instruments such as genes to correct for the endogeneity of health status, the omission of comorbid conditions and behaviors may present a misleading picture of the causal relation between particular health states and academic performance among other outcomes. ${ }^{52}$

\section{Conclusions}

Understanding the consequences of growing up in poor health for adolescent development is an important research question. This question is particularly interesting to policymakers since part of the explicit rationale for programs such as Medicaid is to improve the development of children. However, it is challenging to address due to endogeneity that arises from omitted variables and measurement error problems pertaining to health.

In this paper, we use information on genetic markers to overcome these challenges and identify the causal effect of health on education via an instrumental variables strategy. The explicit use of

\footnotetext{
${ }^{52}$ This may be due to the fact that the genes are associated with more than one health outcome in a vector. But if genetic markers cannot separate one health outcome from another, it is hard to imagine that any nurture or environmental factor could break the statistical association between these disorders. This issue does not have a simple solution.
} 
genetic markers in empirical social science research is becoming possible due to an ever increasing understanding of how genetic inheritance relates to individual health outcomes as well as knowledge from the human genome project. While the decoding of the human genome has been compared to breakthroughs such as Galileo's celestial searching or sending a man to the moon since it has the potential to revolutionize medical treatments, we believe that it also has the ability to shed light on open questions in the social sciences. For example, the interactions and dynamics between health behavior and health status together with the information on genes might really be important in a line of research that tries to assess the impact of health as a form of human capital on many outcomes of interest to economists such as labor market activity, marriage and educational attainment.

We find strong statistical evidence that genetic markers indeed show a great deal of promise as a set of instrumental variables for several health outcomes and behaviors. Using these genes as a novel source of identification we find that the impact of poor health on academic achievement is large. Depression and inattention both lead to a 0.5 point decrease on GPA, which is roughly a one standard deviation reduction in performance. There exists substantial heterogeneity in the impacts of health status on academic performance as female adolescents are strongly adversely affected by negative physical and mental health conditions, whereas males are not significantly impacted. In addition, we find that it is very important for researchers in explaining health status to account for comorbid health disorders as well as endogenous health enhancing or health deteriorating behaviors. Our evidence indicates that either treating these behaviors as exogenous or ignoring comorbid conditions would lead to either different signed estimates or substantially larger impacts of health 
on education.

Unfortunately, the results also lead to more questions, particularly in understanding why females and not males are so adversely affected by poor health outcomes. More research is needed to further our understanding on this issue. For example, responses to a variety of psychological questionnaires can be used to shed light on possible differences between females and males in their self-perception. Future research could also incorporate additional dynamics such as how parents, teachers and peers respond to an individual's changing health state to explore more deeply some of the sources for this heterogeneity. In conclusion, recent years have witnessed an explosion of findings on the causes and correlates of health outcomes and behaviors in neurobiology, which could offer a promising source of predetermined exogenous variations to help identify the impact of health on a set of outcomes of great interest to economists. 


\section{References}

[1] Almond, Douglas, Kenneth Y. Chay and David S. Lee (2005), "The Costs of Low Birth Weight," forthcoming in Quarterly Journal of Economics.

[2] Angrist, Joshua D., Guido W. Imbens, and Donald B. Rubin (1996), "Identification of Causal Effects Using Instrumental Variables," Journal of the American Statistical Association, 91 444472 .

[3] Angrist, Joshua D. and Guide W. Imbens (1995), "Two-State Least Squares Estimation of Average Causal Effects in Models with Variable Treatment Intensity," Journal of the American Statistical Association, 90 431-442.

[4] Audrain-McGovern, Janet, Daniel Rodriguez, Kenneth P. Tercyak, Jocelyn Cuevas, Kelli Rodgers and Freda Patterson (2004), "Identifying and Characterizing Adolescent Smoking Trajectories," Cancer Epidemiology Biomarkers 83 Prevention, 13, 2023-2034.

[5] Audrain-McGovern, Janet, Kenneth P. Tercyak, Paula Goldman and Angelita Bush (2002), "Recruiting Adolescents into Genetic Studies of Smoking Behavior," Cancer Epidemiology Biomarkers $\&$ Prevention, 11, 249-52.

[6] Barkley, Russell A. and Kevin R. Murphy (1998), Attention-Deficit/Hyperactivity Disorder: A Clinical Workbook (2nd ed), New York: The Guilford Press.

[7] Bannon Michael J., Paola Sacchetti and James G. Granneman (1995), "The Dopamine Transporter: Potential Involvement in Neuropsychiatric Disorders" in Floyd E. Borroni and David J. Kupfer (eds.), Psychopharmacology: The Fourth Generation of Progress, New York: Raven Press Ltd., 179-188.

[8] Beardslee William R., S. Swatling, L. Hoke, L, P. C. Rothberg, P. van de Velde, L. Focht and D. Podorefsky (1998), "From Cognitive Information to Shared Meaning: Healing Principles in Prevention Intervention," Psychiatry, 61(2), 112-130.

[9] Becker, Gary S. (1993), Human Capital: A Theoretical and Empirical Analysis with Special Reference to Education (3d edition), Chicago: The University of Chicago Press.

[10] Behrman, Jere R. and Mark R. Rosenzweig (2004), "Returns to Birthweight," Review of Economics and Statistics, 86, 586-601.

[11] Behrman, Jere R. and Victor Lavy (1998), "Child Health and Schooling Achievement: Association, Causality and Household Allocations," CARESS Working Papres 97-23, University of Pennsylvania. 
[12] Behrman, Jere R., Mark R. Rosenzweig and Paul Taubman (1994), "Endowments and the Allocation of Schooling in the Family and in the Marriage Market: The Twins Experiment," Journal of Political Economy, 102, 1131-1174.

[13] Biederman Joseph, Stephen Faraone, Eric Mick and Elise Lelon (1995), "Psychiatric comorbidity among referred juveniles with major depression: fact or artifact?," Journal of American Academy of Child and Adolescent Psychiatry, 34, 579-590

[14] Blum, Kenneth, Ernest P. Noble, Paul J. Sheridan, Olivia Finley, Anne Montgomery, Terry Ritchie, Tulin Ozkaragoz, Robert J. Fitch, Frank Sadlack, Donald Sheffield, Tommie Dahlmann, Sheryl Halbardier and Harou Nogami (1991), "Association of the A1 Allele of the D2 Dopamine Receptor Gene with Severe Alcoholism," Alcohol, 8, 409-416.

[15] Boardman, Anthony E. and Richard J. Murnane (1979), "Using Panel Data to Improve Estimates of the Determinants of Educational Attainment," Sociology of Education, 52, 113-121.

[16] Bound John and Gary Solon (1999), "Double Trouble: On the Value of Twins-Based Estimation of the Return to Schooling", Economics of Education Review, 18, 169-182.

[17] Carr, Laurence A., J. Khristen Basham, Brian K. York and Peter P. Rowell (1992), "Inhibition of Uptake of l-methyl-4-phenylpyridinium Ion and Dopamine in Striatal Synaptosomes by Tobacco Smoke Components," European Journal of Pharmacology, 215, 285-287.

[18] Coger, Roger W., Kathryn L. Moe and E. A. Serafetinides (1996), "Attention deficit disorder in adults and nicotine dependence: Psychobiological factors in resistance to recovery?", Journal of Psychoactive Drugs, 28(3), 229-240.

[19] Comings, David E., Radhika Gade-Andavolu, Nancy Gonzalez, Shijuan Wu, Donn Muhleman, Hezekiah Blake, Fumin Chiu, Edward Wang, K Farwell, Salima Darakjy, Richard Baker, George Dietz, Gerard Saucier and James P MacMurray (2000), "Multivariate Analysis of Associations of 42 Genes in ADHD, ODD and Conduct Disorder," Clinical Genetics, 58(1), 31-40.

[20] Comings, David E., S. Wu, Connie Chiu, Robert H. Ring, Radhika Gade, Chul Ahn, James P. MacMurray, George Dietz and Donn Muhleman (1996), "Polygenic Inheritance of Tourette Syndrome, Stuttering, Attention Deficit Hyperactivity, Conduct, and Oppositional Defiant Disorder: The Additive and Subtractive Effect of the Three Dopaminergic Genes-DRD2, D beta H, and DAT1," American Journal Of Medical Genetics, 67, 264-288.

[21] Conners, Keith C., Edward D. Levin, Elizabeth Sparrow, Sean C. Hinton, D. Erhardt, W. H. Meck, J. E. Rose and J. March (1996), "Nicotine and attention in adult attention deficit hyperactivity disorder (ADHD)", Psychopharmacology Bulletin, 32(1), 67-73. 
[22] Cook, Edward H. Jr., Mark A. Stein, Matthew D. Krasowski, Nancy J. Cox, D. M. Olkon, J. E. Kieffer and Bennett L. Leventhal (1995), "Association of Attention-Deficit Disorder and the Dopamine Transporter Gene," American Journal of Human Genetics, 56, 993-998.

[23] Currie, Janet (2005), "Health Disparities and Gaps in School Readiness," Future of Children,15(1), 117-138.

[24] Currie, Janet and Mark Stabile (2005), "Child Mental Health and Human Capital Accumulation: The Case of ADHD," NBER Working Paper: 10435.

[25] Currie, Janet and Rosemary Hyson (1999), "Is the Impact of Health Shocks Cushioned by Socioeconomic Status? The Case of Low Birthweight," American Economic Review, 89(2), 245-250.

[26] Cutler, David and Edward Glaeser (2005), "What Explains Differences in Smoking, Drinking and Other Health-Related Behaviors?" Cambridge: NBER Working Paper w11100.

[27] Di Chiara, Gaetaro. and Assunta Imperto (1988), "Drugs Abused by Humans Preferentially Increase Synaptic Dopamine Concentrations in the Mesolimbic System of Freely Moving Rats," Proceedings of the National Academy of Sciences USA, 85, 5274-5278.

[28] Ding, Weili, and Steven F. Lehrer (2005), "Accounting for Unobserved Ability Heterogeneity within Education Production Functions," mimeo, Queen's University.

[29] Evans, William and Edward Montgomery (1994), "Education and Health: Where There's Smoke There's an Instrument." NBER Working Paper: 4949

[30] Epstein, Leonard H., Jodie L. Jaroni, Rocco A. Paluch, John J. Leddy, Holly E. Vahue, Larry Hawk, E. Paul Wileyto, Peter G. Shields, and Caryn Lerman (2002), "Dopamine Transporter Genotype as a Risk Factor for Obesity in Smokers," Obesity Research, 10(12), 1232-1240.

[31] Farrell, Phillip and Victor R. Fuchs (1982), "Schooling and Health: The Cigarette Connection," Journal of Health Economics, 1(3), 217-230.

[32] Fuchs, Victor R. (1982), "Time Preference and Health: An Explanatory Study" in Victor R. Fuchs ed. Economic Aspects of Health, University of Chicago Press for NBER, Chicago.

[33] Glewwe, Paul and Hanan Jacoby (1995), "An Economic Analysis of Delayed Primary School Enrollment in a Low-Income Country-the Role of Early Childhood Nutrition," Review of Economics and Statistics, 77, 156-169. 
[34] Gringras, Paul and Wai Chen (2001), "Mechanisms for Differences in Monozygous Twins," Early Human Development, 64(2), 105-117.

[35] Grossman, Michael and Robert Kaestner (1997), "Effects of Education on Health," in Jere R. Behrman and Nezver Stacey eds. The Social Benefits of Education, University of Michigan Press, Ann Arbor.

[36] Grossman, Michael (1975), "The Correlation between Health and Schooling," in Household Production and Consumption, Ed N. E. Terleckyj, Studies in Income and Wealth, Vol. 40, Conference on Research in Income and Wealth. New York: Columbia University Press for the National Bureau of Economic Research,

[37] Grossman, Michael (1972), "On the Concept of Health Capital and the Demand for Health," Journal of Political Economy, 80(2), 223-255.

[38] Hamermesh, Dan (2000), "The Craft of Labormetrics," Industrial and Labor Relations Review, 53(3), 363-380.

[39] Imbens, Guido W. and Joshua D. Angrist (1994), "Identification and Estimation of Local Average Treatment Effects," Econometrica, 62, 467-475.

[40] Kenkel, Donald (1991), "Health Behavior, Health Knowledge and Schooling," Journal of Political Economy, 99(2), 287-305.

[41] Klein, Daniel N., Peter M. Lewinsohn and John R. Seeley (1997a), "Psychosocial Characteristics of Adolescents with a Past History of Dysthymic Disorder: Comparison with Adolescents with Past Histories of Major Depressive and Non-Affective Disorders, and Never Mentally Ill Controls," Journal of Affective Disorders, 42, 127-135.

[42] Kremer Michael and Edward Miguel (2004), "Worms: Identifying Impacts on Education and Health in the Presence of Treatment Externalities," Econometrica, 72(1), 159-217.

[43] Lerman, Caryn, Neil E. Caporaso, Angelita Bush, Yun-Ling Zheng, Janet Audrain, David Main and Peter G. Shields (2001), "Tryptophan Hydroxylase Gene Variant and Smoking Behavior," American Journal of Medical Genetics, 105(6), 518-520.

[44] Lerman, Caryn, and Wade Berrettini (2003), "Elucidating the Role of Genetic Factors in Smoking Behavior and Nicotine Dependence," American Journal of Medical Genetics (Neuropsychiatric Genetics), 118B, 48-54. 
[45] Levin, Edward D., Keith C. Conners, Elizabeth Sparrow, Sean C. Hinton, D. Erhardt, W.H. Meck, J.E. Rose and J. March (1996), "Nicotine effects on adults with attentiondeficit/hyperactivity disorder", Psychopharmacology, 123 55-63.

[46] Lucki, Irwin, (1998), "The Spectrum of Behaviors Influenced by Serotonin," Biological Psychiatry, 44(3), 151-162.

[47] Mays Jr., Herman L. and Geoffrey E. Hill, "Choosing Mates : Good Genes versus Genes that are a Good Fit", Trends in Ecology and Evolution, 10(19), 554-559.

[48] McClure, Samuel M., David I. Laibson, George Loewenstein and Jonathan D. Cohen (2004), "Separate Neural Systems. Value Immediate and Delayed. Monetary Rewards," Science, 306, 503-507.

[49] Miller, David C. (2005), "Adolescent Cigarette Smoking: A Longitudinal Analysis Through Young Adulthood," NCES Working Paper \#2005333

[50] Neumark, David (1999), "Biases in Twin Estimates of the Return to Schooling," Economics of Education Review, 18, 143-148.

[51] Olds, James, (1967), "The Limbic System and Behavioral Reinforcement," Progress in Brain Research, 27, 144-64.

[52] Perri, Timothy J. (1984), Health Status and Schooling Decisions of Young Men, Economics of Education Review, 3, 207-213.

[53] Perusse, Louis, Tuomo Rankinen, Aamir Zuberi, Yvon C. Chagnon, S. John Weisnagel, George Argyropoulos, Brandon Walts, Eric E. Snyder and Claude Bouchard (2005), "The Human Obesity Gene Map: The 2004 Update," Obesity Research, 13, 381-490.

[54] Pliszka S. R., C. L. Carlson, J. M. Swanson (1999), ADHD with Comorbid Disorders: Clinical Assessment and Mangement, New York: Guilford Press.

[55] Pomerleau, Ovide F., Karen K. Downey, Fred W. Stelson and Cynthia S. Pomerleau (1995), "Cigarette smoking in adult patients diagnosed with attention deficit hyperactivity disorder", Journal of Substance Abuse, 7(3), 373-378.

[56] Roberts, Craig S. and Morris L. Gosling (2003), "Genetic Quality and Similarity Interact in Mate Choice Decisions by Female Mice," Nature Genetics, 35, 103-106. 
[57] Roberts, Robert E., Peter M. Lewinsohn, and John R. Seeley (1991), "Screening for Adolescent Depression: Comparison of Depression Scales," Journal of the American Academy of Child and Adolescent Psychiatry, 30, 58-66.

[58] Rosenzweig, Mark R. and Theodore. P. Schultz (1983), "Estimating a Household Production Function: Heterogeneity, the Demand for Health, Inputs, and Their Effects on Birth Weight," Journal of Political Economy, 91, 723-746.

[59] Seeman, Philip, and Hyman B. Niznik (1990), "Dopamine Receptors and Transporters in Parkinson's Disease and Schizophrenia," The FASEB Journal, 4, 2737-2744.

[60] Sibley, David R. and Frederick J. Monsma, Jr. (1992), "The Molecular Biology of the Dopamine Receptors", Trends in Pharmacological Science, 13, 61-68.

[61] Schwimmer, Jeffrey B., Tasha M. Burwinkle and James W. Varni (2003), "Health-Related Quality of Life of Severely Obese Children and Adolescents," Journal of American Medical Association, 289, 1813-1819.

[62] Strauss, John and Duncan Thomas (1998), "Health, Nutrition, and Economic Development," Journal of Economic Literature, 36(2), 766-817.

[63] Todd, Petra E. and Kenneth I. Wolpin (2004), "The Production of Cognitive Achievement in Children: Home, School and Racial Test Score Gaps," mimeo, University of Pennsylvania.

[64] Venter, J. Craig, Mark D. Adams, Eugene W. Myers, Peter W. Li, Richard J. Mural, Granger G. Sutton, Hamilton O. Smith, Mark Yandell, Cheryl A. Evans, Robert A. Holt, Jeannine D. Gocayne, Peter Amanatides, Richard M. Ballew, Daniel H. Huson, Jennifer Russo Wortman, Qing Zhang, Chinnappa D. Kodira, Xiangqun H. Zheng, Lin Chen, Marian Skupski, Gangadharan Subramanian, Paul D. Thomas, Jinghui Zhang, George L. Gabor Miklos, Catherine Nelson, Samuel Broder, Andrew G. Clark, Joe Nadeau, Victor A. McKusick, Norton Zinder, Arnold J. Levine, Richard J. Roberts, Mel Simon, Carolyn Slayman, Michael Hunkapiller, Randall Bolanos, Arthur Delcher, Ian Dew, Daniel Fasulo, Michael Flanigan, Liliana Florea, Aaron Halpern, Sridhar Hannenhalli, Saul Kravitz, Samuel Levy, Clark Mobarry, Knut Reinert, Karin Remington, Jane Abu-Threideh, Ellen Beasley, Kendra Biddick, Vivien Bonazzi, Rhonda Brandon, Michele Cargill, Ishwar Chandramouliswaran, Rosane Charlab, Kabir Chaturvedi, Zuoming Deng, Valentina Di Francesco, Patrick Dunn, Karen Eilbeck, Carlos Evangelista, Andrei E. Gabrielian, Weiniu Gan, Wangmao Ge, Fangcheng Gong, Zhiping Gu, Ping Guan, Thomas J. Heiman, Maureen E. Higgins, Rui-Ru Ji, Zhaoxi Ke, Karen A. Ketchum, Zhongwu Lai, Yiding Lei, Zhenya Li, Jiayin Li, Yong Liang, Xiaoying Lin, Fu Lu, Gennady V. Merkulov, Natalia Milshina, Helen M. Moore, Ashwinikumar K Naik, Vaibhav A. Narayan, Beena Neelam, Deborah 
Nusskern, Douglas B. Rusch, Steven Salzberg, Wei Shao, Bixiong Shue, Jingtao Sun, Zhen Yuan Wang, Aihui Wang, Xin Wang, Jian Wang, Ming-Hui Wei, Ron Wides, Chunlin Xiao, Chunhua Yan, Alison Yao, Jane Ye, Ming Zhan, Weiqing Zhang, Hongyu Zhang, Qi Zhao, Liansheng Zheng, Fei Zhong, Wenyan Zhong, Shiaoping C. Zhu, Shaying Zhao, Dennis Gilbert, Suzanna Baumhueter, Gene Spier, Christine Carter, Anibal Cravchik, Trevor Woodage, Feroze Ali, Huijin An, Aderonke Awe, Danita Baldwin, Holly Baden, Mary Barnstead, Ian Barrow, Karen Beeson, Dana Busam, Amy Carver, Angela Center, Ming Lai Cheng, Liz Curry, Steve Danaher, Lionel Davenport, Raymond Desilets, Susanne Dietz, Kristina Dodson, Lisa Doup, Steven Ferriera, Neha Garg, Andres Gluecksmann, Brit Hart, Jason Haynes, Charles Haynes, Cheryl Heiner, Suzanne Hladun, Damon Hostin, Jarrett Houck, Timothy Howland, Chinyere Ibegwam, Jeffery Johnson, Francis Kalush, Lesley Kline, Shashi Koduru, Amy Love, Felecia Mann, David May, Steven McCawley, Tina McIntosh, Ivy McMullen, Mee Moy, Linda Moy, Brian Murphy, Keith Nelson, Cynthia Pfannkoch, Eric Pratts, Vinita Puri, Hina Qureshi, Matthew Reardon, Robert Rodriguez, Yu-Hui Rogers, Deanna Romblad, Bob Ruhfel, Richard Scott, Cynthia Sitter, Michelle Smallwood, Erin Stewart, Renee Strong, Ellen Suh, Reginald Thomas, Ni Ni Tint, Sukyee Tse, Claire Vech, Gary Wang, Jeremy Wetter, Sherita Williams, Monica Williams, Sandra Windsor, Emily Winn-Deen, Keriellen Wolfe, Jayshree Zaveri, Karena Zaveri, Josep F. Abril, Roderic Guigó, Michael J. Campbell, Kimmen V. Sjolander, Brian Karlak, Anish Kejariwal, Huaiyu Mi, Betty Lazareva, Thomas Hatton, Apurva Narechania, Karen Diemer, Anushya Muruganujan, Nan Guo, Shinji Sato, Vineet Bafna, Sorin Istrail, Ross Lippert, Russell Schwartz, Brian Walenz, Shibu Yooseph, David Allen, Anand Basu, James Baxendale, Louis Blick, Marcelo Caminha, John Carnes-Stine, Parris Caulk, Yen-Hui Chiang, My Coyne, Carl Dahlke, Anne Deslattes Mays, Maria Dombroski, Michael Donnelly, Dale Ely, Shiva Esparham, Carl Fosler, Harold Gire, Stephen Glanowski, Kenneth Glasser, Anna Glodek, Mark Gorokhov, Ken Graham, Barry Gropman, Michael Harris, Jeremy Heil, Scott Henderson, Jeffrey Hoover, Donald Jennings, Catherine Jordan, James Jordan, John Kasha, Leonid Kagan, Cheryl Kraft, Alexander Levitsky, Mark Lewis, Xiangjun Liu, John Lopez, Daniel Ma, William Majoros, Joe McDaniel, Sean Murphy, Matthew Newman, Trung Nguyen, Ngoc Nguyen, Marc Nodell, Sue Pan, Jim Peck, Marshall Peterson, William Rowe, Robert Sanders, John Scott, Michael Simpson, Thomas Smith, Arlan Sprague, Timothy Stockwell, Russell Turner, Eli Venter, Mei Wang, Meiyuan Wen, David Wu, Mitchell Wu, Ashley Xia, Ali Zandieh, and Xiaohong Zhu (2001), "The Sequence of the Human Genome," Science, 291, 1304-1351. 
Table 1: Summary Characteristics of the Sample

\begin{tabular}{|c|c|c|c|c|c|c|}
\hline \multicolumn{7}{|c|}{ Time Invariant Variables $\mathbf{N}=893$} \\
\hline \multicolumn{2}{|l|}{ Variable } & \multicolumn{3}{|c|}{ Mean } & \multicolumn{2}{|c|}{ Standard Deviation } \\
\hline \multicolumn{2}{|l|}{ Male } & \multicolumn{3}{|c|}{0.469} & \multicolumn{2}{|c|}{0.499} \\
\hline \multicolumn{2}{|l|}{ African American } & \multicolumn{3}{|c|}{0.073} & \multicolumn{2}{|c|}{0.260} \\
\hline \multicolumn{2}{|l|}{ Hispanic } & \multicolumn{3}{|c|}{0.093} & \multicolumn{2}{|c|}{0.291} \\
\hline \multicolumn{2}{|l|}{ Asian } & \multicolumn{3}{|c|}{0.106} & \multicolumn{2}{|c|}{0.308} \\
\hline \multicolumn{2}{|l|}{ Caucasian } & \multicolumn{3}{|c|}{0.667} & \multicolumn{2}{|c|}{0.471} \\
\hline \multicolumn{2}{|l|}{ Biological Parent smoked } & \multicolumn{3}{|c|}{0.449} & \multicolumn{2}{|c|}{0.498} \\
\hline \multicolumn{2}{|l|}{ Body Mass Index } & \multicolumn{3}{|c|}{23.426} & \multicolumn{2}{|c|}{4.410} \\
\hline \multicolumn{2}{|l|}{ Obese (BMI $>=30)$} & \multicolumn{3}{|c|}{0.081} & \multicolumn{2}{|c|}{0.272} \\
\hline \multicolumn{2}{|l|}{ School 1} & \multicolumn{3}{|c|}{0.176} & & \\
\hline School 2 & & & 0.249 & & & 32 \\
\hline School 3 & & & 0.214 & & & 10 \\
\hline School 4 & & & 0.138 & & & 45 \\
\hline School 5 & & & 0.227 & & & 19 \\
\hline AD diagnosis & & & 0.043 & & & 02 \\
\hline HD diagnosis & & & 0.040 & & & 97 \\
\hline ADHD diagnosis & & & 0.063 & & & 43 \\
\hline & & Time Vary & Variabl & & & \\
\hline & $\begin{array}{l}\text { Grade } \\
10 \text { Mean }\end{array}$ & $\begin{array}{l}\text { Grade } 10 \\
\text { Standard } \\
\text { Deviation }\end{array}$ & $\begin{array}{l}\text { Grade } \\
11 \\
\text { Mean }\end{array}$ & \begin{tabular}{|l|} 
Grade 11 \\
Standard \\
Deviation \\
\end{tabular} & $\begin{array}{l}\text { Grade } \\
12 \\
\text { Mean }\end{array}$ & $\begin{array}{l}\text { Grade } 12 \\
\text { Standard } \\
\text { Deviation }\end{array}$ \\
\hline Tried Smoking & 0.433 & 0.495 & 0.483 & 0.500 & 0.533 & 0.499 \\
\hline Current Smoker & 0.091 & 0.288 & 0.152 & 0.359 & 0.178 & 0.382 \\
\hline $\begin{array}{l}\text { Years as a Regular } \\
\text { Smoker }\end{array}$ & 0.116 & 0.398 & 0.245 & 0.680 & 0.399 & 0.968 \\
\hline Currently depressed & 0.161 & 0.368 & 0.117 & 0.322 & $\mathrm{~N} / \mathrm{A}$ & $\mathrm{N} / \mathrm{A}$ \\
\hline Smoker in Household & 0.241 & 0.428 & 0.246 & 0.431 & 0.231 & 0.422 \\
\hline $\begin{array}{l}\text { Grade Point Average } \\
\text { (GPA) }\end{array}$ & 3.184 & 0.567 & 3.148 & 0.598 & 3.176 & 0.571 \\
\hline Age & 16.032 & 0.399 & 17.030 & 0.396 & 18.034 & 0.400 \\
\hline Depressed last period & 0.168 & 0.374 & 0.169 & 0.375 & 0.122 & 0.327 \\
\hline Smoker last period & 0.088 & 0.283 & 0.095 & 0.293 & 0.147 & 0.354 \\
\hline $\begin{array}{l}\text { Lagged number of years } \\
\text { smoking }\end{array}$ & 0.071 & 0.278 & 0.120 & 0.406 & 0.235 & 0.662 \\
\hline Number of observations & & 34 & & 863 & & 879 \\
\hline
\end{tabular}


Table 2: Summary Information on Genetic Markers in the Sample

\begin{tabular}{|c|c|c|c|c|c|c|}
\hline Gene & Marker & $\begin{array}{l}\text { Total } \\
\text { Number } \\
\text { of } \\
\text { People } \\
\end{array}$ & $\begin{array}{l}\text { Number } \\
\text { of people } \\
\text { also have } \\
\text { AA }\end{array}$ & $\begin{array}{l}\text { Number } \\
\text { of people } \\
\text { also have } \\
\text { TT }\end{array}$ & $\begin{array}{l}\text { Number of } \\
\text { people also } \\
\text { have A1A1 }\end{array}$ & $\begin{array}{l}\text { Number } \\
\text { of people } \\
\text { also have } \\
\text { DAT0 }\end{array}$ \\
\hline \multirow[t]{3}{*}{ GenoTPH } & AA & $\begin{array}{c}120 \\
{[0.135]}\end{array}$ & $* * * *$ & $\begin{array}{c}4 \\
(0.033)\end{array}$ & $\begin{array}{c}5 \\
(0.042)\end{array}$ & $\begin{array}{c}16 \\
(0.133)\end{array}$ \\
\hline & $\mathrm{AC}$ & $\begin{array}{c}393 \\
{[0.440]}\end{array}$ & $* * * *$ & $\begin{array}{c}15 \\
(0.038)\end{array}$ & $\begin{array}{c}20 \\
(0.051)\end{array}$ & $\begin{array}{c}39 \\
(0.099)\end{array}$ \\
\hline & CC & $\begin{array}{c}380 \\
{[0.426]}\end{array}$ & $* * * *$ & $\begin{array}{c}12 \\
(0.032)\end{array}$ & $\begin{array}{c}27 \\
(0.071)\end{array}$ & $\begin{array}{c}65 \\
(0.171)\end{array}$ \\
\hline \multirow[t]{3}{*}{ GenoCYP } & TT & $\begin{array}{c}31 \\
{[0.035]}\end{array}$ & $\begin{array}{c}4 \\
(0.129)\end{array}$ & $* * * *$ & $\begin{array}{c}2 \\
(0.065)\end{array}$ & $\begin{array}{c}3 \\
(0.097)\end{array}$ \\
\hline & CT & $\begin{array}{c}191 \\
{[0.214]}\end{array}$ & $\begin{array}{c}24 \\
(0.126)\end{array}$ & **** & $\begin{array}{c}9 \\
(0.047)\end{array}$ & $\begin{array}{c}19 \\
(0.099)\end{array}$ \\
\hline & $\mathrm{CC}$ & $\begin{array}{c}671 \\
{[0.751]}\end{array}$ & $\begin{array}{c}92 \\
(0.137)\end{array}$ & $* * * *$ & $\begin{array}{c}41 \\
(0.061)\end{array}$ & $\begin{array}{c}56 \\
(0.083)\end{array}$ \\
\hline \multirow[t]{3}{*}{ DRD2 } & A1A1 & $\begin{array}{c}52 \\
{[0.058]}\end{array}$ & $\begin{array}{c}5 \\
(0.096)\end{array}$ & $\begin{array}{c}2 \\
(0.038)\end{array}$ & $* * * *$ & $\begin{array}{c}3 \\
(0.058)\end{array}$ \\
\hline & A1A2 & $\begin{array}{c}286 \\
{[0.320]}\end{array}$ & $\begin{array}{c}34 \\
(0.119)\end{array}$ & $\begin{array}{c}9 \\
(0.031)\end{array}$ & $* * * *$ & $\begin{array}{c}19 \\
(0.066)\end{array}$ \\
\hline & A2A2 & $\begin{array}{c}555 \\
{[0.622]}\end{array}$ & $\begin{array}{c}81 \\
(0.146)\end{array}$ & $\begin{array}{c}20 \\
(0.036)\end{array}$ & $* * * *$ & $\begin{array}{c}56 \\
(0.101)\end{array}$ \\
\hline \multirow[t]{3}{*}{ DAT } & DAT0 & $\begin{array}{c}72 \\
{[0.081]}\end{array}$ & $\begin{array}{c}16 \\
(0.222)\end{array}$ & $\begin{array}{c}3 \\
(0.042)\end{array}$ & $\begin{array}{c}3 \\
(0.042)\end{array}$ & $* * * *$ \\
\hline & DAT1 & $\begin{array}{c}317 \\
{[0.355]}\end{array}$ & $\begin{array}{c}38 \\
(0.120)\end{array}$ & $\begin{array}{c}13 \\
(0.041)\end{array}$ & $\begin{array}{c}17 \\
(0.054)\end{array}$ & $* * * *$ \\
\hline & DAT2 & $\begin{array}{c}498 \\
{[0.558]}\end{array}$ & $\begin{array}{c}65 \\
(0.131)\end{array}$ & $\begin{array}{c}15 \\
(0.030)\end{array}$ & $\begin{array}{c}32 \\
(0.064)\end{array}$ & $* * * *$ \\
\hline
\end{tabular}

Note: Each cell contains the number of individuals that possess the respective row and column combination of genetic markers. The conditional frequency of having the dual markers is presented in round parentheses. The marginal frequency of possessing a marker is presented in square parentheses. 
Table 3: Relationship Between Genetic Markers with Health Behaviors and Health Outcomes During Adolescence

\begin{tabular}{|c|c|c|c|c|c|c|c|c|}
\hline Gene & Marker & $\begin{array}{l}\text { Depressi } \\
\text { on }\end{array}$ & Smoking & Obesity & BMI & ADHD & $\mathrm{AD}$ & HD \\
\hline \multirow[t]{3}{*}{ GenoTPH } & AA & $\begin{array}{c}0.149 \\
(0.357) \\
{[0.176]}\end{array}$ & $\begin{array}{c}0.158 \\
(0.365) \\
{[0.188]^{*}}\end{array}$ & $\begin{array}{c}0.108 \\
(0.312) \\
{[0.122]}\end{array}$ & $\begin{array}{l}23.939 \\
(4.516)\end{array}$ & $\begin{array}{c}0.067 \\
(0.250) \\
{[0.071]}\end{array}$ & $\begin{array}{c}0.033 \\
(0.180) \\
{[0.035]}\end{array}$ & $\begin{array}{c}0.033 \\
(0.180) \\
{[0.035]}\end{array}$ \\
\hline & AC & $\begin{array}{c}0.150 \\
(0.357) \\
{[0.178]}\end{array}$ & $\begin{array}{c}0.105 \\
(0.306) \\
{[0.117]}\end{array}$ & $\begin{array}{c}0.074 \\
(0.262) \\
{[0.080]}\end{array}$ & $\begin{array}{l}23.291 \\
(4.140)\end{array}$ & $\begin{array}{c}0.074 \\
(0.262) \\
{[0.080]}\end{array}$ & $\begin{array}{c}0.048 \\
(0.215) \\
{[0.051]}\end{array}$ & $\begin{array}{c}0.043 \\
(0.204) \\
{[0.045]}\end{array}$ \\
\hline & CC & $\begin{array}{c}0.156 \\
(0.363) \\
{[0.185]}\end{array}$ & $\begin{array}{c}0.101 \\
(0.301) \\
{[0.112]}\end{array}$ & $\begin{array}{c}0.079 \\
(0.270) \\
{[0.086]}\end{array}$ & $\begin{array}{l}23.403 \\
(4.640)\end{array}$ & $\begin{array}{c}0.050 \\
(0.218) \\
{[0.053]}\end{array}$ & $\begin{array}{c}0.039 \\
(0.195) \\
{[0.041]}\end{array}$ & $\begin{array}{c}0.039 \\
(0.195) \\
{[0.041]}\end{array}$ \\
\hline \multirow[t]{3}{*}{ GenoCYP } & TT & $\begin{array}{c}0.165 \\
(0.373) \\
{[0.197]}\end{array}$ & $\begin{array}{c}0.121 \\
(0.328) \\
{[0.138]}\end{array}$ & $\begin{array}{c}0.032 \\
(0.180) \\
{[0.033]} \\
\end{array}$ & $\begin{array}{l}22.536 \\
(3.283)\end{array}$ & $\begin{array}{c}0.129 \\
(0.341) \\
{[0.148]} \\
\end{array}$ & $\begin{array}{c}0.129 \\
(0.341) \\
{[0.148]^{*}}\end{array}$ & $\begin{array}{c}0.097 \\
(0.301) \\
{[0.104]^{*+*+}}\end{array}$ \\
\hline & CT & $\begin{array}{c}0.159 \\
(0.366) \\
{[0.189]}\end{array}$ & $\begin{array}{c}0.111 \\
(0.315) \\
{[0.125]}\end{array}$ & $\begin{array}{c}0.058 \\
(0.234) \\
{[0.061]}\end{array}$ & $\begin{array}{l}23.082 \\
(4.195)\end{array}$ & $\begin{array}{c}0.031 \\
(0.175) \\
{[0.032]^{* *}}\end{array}$ & $\begin{array}{c}0.010 \\
(0.102) \\
{[0.011]^{*}}\end{array}$ & $\begin{array}{c}0.026 \\
(0.160) \\
{[0.027]} \\
\end{array}$ \\
\hline & CC & $\begin{array}{c}0.150 \\
(0.357) \\
{[0.177]}\end{array}$ & $\begin{array}{c}0.109 \\
(0.312) \\
{[0.123]}\end{array}$ & $\begin{array}{c}0.089 \\
(0.286) \\
{[0.098]}\end{array}$ & $\begin{array}{l}23.565 \\
(4.508)\end{array}$ & $\begin{array}{c}0.069 \\
(0.253) \\
{[0.074]}\end{array}$ & $\begin{array}{c}0.048 \\
(0.213) \\
{[0.050]}\end{array}$ & $\begin{array}{c}0.042 \\
(0.200) \\
{[0.044]}\end{array}$ \\
\hline \multirow[t]{3}{*}{ DRD2 } & A1A1 & $\begin{array}{c}0.189 \\
(0.393) \\
{[0.233]}\end{array}$ & $\begin{array}{c}0.122 \\
(0.328) \\
{[0.138]}\end{array}$ & $\begin{array}{c}0.096 \\
(0.298) \\
{[0.106]}\end{array}$ & $\begin{array}{l}23.562 \\
(5.998)\end{array}$ & $\begin{array}{c}0.058 \\
(0.235) \\
{[0.061]}\end{array}$ & $\begin{array}{c}0.038 \\
(0.194) \\
{[0.040]}\end{array}$ & $\begin{array}{c}0.038 \\
(0.194) \\
{[0.040]}\end{array}$ \\
\hline & A1A2 & $\begin{array}{c}0.174 \\
(0.380) \\
{[0.211]}\end{array}$ & $\begin{array}{c}0.100 \\
(0.301) \\
{[0.112]}\end{array}$ & $\begin{array}{c}0.115 \\
(0.320) \\
{[0.130]^{*}}\end{array}$ & $\begin{array}{l}23.860 \\
(4.651)\end{array}$ & $\begin{array}{c}0.049 \\
(0.216) \\
{[0.051]}\end{array}$ & $\begin{array}{c}0.021 \\
(0.144) \\
{[0.021]}\end{array}$ & $\begin{array}{c}0.035 \\
(0.184) \\
{[0.036]}\end{array}$ \\
\hline & A2A2 & $\begin{array}{c}0.138 \\
(0.345) \\
{[0.160]^{*}}\end{array}$ & $\begin{array}{c}0.114 \\
(0.318) \\
{[0.129]}\end{array}$ & $\begin{array}{c}0.061 \\
(0.240) \\
{[0.065]^{*}}\end{array}$ & $\begin{array}{l}23.189 \\
(4.088)\end{array}$ & $\begin{array}{c}0.070 \\
(0.256) \\
{[0.076]}\end{array}$ & $\begin{array}{c}0.054 \\
(0.226) \\
{[0.057]^{*}}\end{array}$ & $\begin{array}{c}0.043 \\
(0.204) \\
{[0.045]}\end{array}$ \\
\hline \multirow[t]{3}{*}{ DAT } & DAT0 & $\begin{array}{c}0.155 \\
(0.363) \\
{[0.183]}\end{array}$ & $\begin{array}{c}0.155 \\
(0.363) \\
{[0.183]}\end{array}$ & $\begin{array}{c}0.077 \\
(0.268) \\
{[0.083]}\end{array}$ & $\begin{array}{l}23.685 \\
(5.310)\end{array}$ & $\begin{array}{c}0.064 \\
(0.247) \\
{[0.069]} \\
\end{array}$ & $\begin{array}{c}0.038 \\
(0.194) \\
{[0.040]} \\
\end{array}$ & $\begin{array}{c}0.051 \\
(0.222) \\
{[0.054]}\end{array}$ \\
\hline & DAT1 & $\begin{array}{c}0.109 \\
(0.311) \\
{[0.139]^{*}}\end{array}$ & $\begin{array}{c}0.122 \\
(0.327) \\
{[0.122]}\end{array}$ & $\begin{array}{c}0.095 \\
(0.293) \\
{[0.105]}\end{array}$ & $\begin{array}{l}23.775 \\
(4.749)\end{array}$ & $\begin{array}{c}0.091 \\
(0.289) \\
{[0.101]^{*}}\end{array}$ & $\begin{array}{c}0.063 \\
(0.244) \\
{[0.067]^{*}}\end{array}$ & $\begin{array}{c}0.060 \\
(0.238) \\
{[0.064]^{*}}\end{array}$ \\
\hline & DAT2 & $\begin{array}{c}0.172 \\
(0.378) \\
{[0.207]^{*}}\end{array}$ & $\begin{array}{c}0.104 \\
(0.306) \\
{[0.116]}\end{array}$ & $\begin{array}{c}0.072 \\
(0.259) \\
{[0.078]}\end{array}$ & $\begin{array}{l}23.161 \\
(4.004)\end{array}$ & $\begin{array}{c}0.044 \\
(0.206) \\
{[0.046]^{*}}\end{array}$ & $\begin{array}{c}0.030 \\
(0.171) \\
{[0.031]^{*}}\end{array}$ & $\begin{array}{c}0.026 \\
(0.160) \\
{[0.027]^{*}}\end{array}$ \\
\hline
\end{tabular}

Note: Each cell presents the conditional mean, the standard deviation in round parentheses and the odds ratio for outcomes (excluding BMI) in square parentheses. *, **, *** denote the Null of homogeneity of odds across markers by genotype from a chi-squared test is rejected at the $1 \%, 5 \%$, $10 \%$ level respectively. The tests were conducted with the same sample used to construct Table 1. 
Table 4: Relationship Between Health Behaviors and Health Outcomes During Adolescence

\begin{tabular}{|c|c|c|c|c|c|c|c|c|}
\hline Behavior & $\begin{array}{l}\text { Total } \\
\text { Number }\end{array}$ & $\begin{array}{l}\text { Nothing } \\
\text { Else }^{1}\end{array}$ & $\begin{array}{l}\text { Also } \\
\text { Smokes }\end{array}$ & $\begin{array}{l}\text { Also } \\
\text { AD }\end{array}$ & $\begin{array}{l}\text { Also } \\
\text { HD }\end{array}$ & $\begin{array}{l}\text { Also } \\
\text { ADHD }\end{array}$ & $\begin{array}{l}\text { Also } \\
\text { Obese }\end{array}$ & $\begin{array}{l}\text { Also } \\
\text { Depressed }\end{array}$ \\
\hline \multicolumn{9}{|c|}{ Wave $3, \mathrm{~N}=834$} \\
\hline Nothing & $\begin{array}{c}471 \\
{[0.565]}\end{array}$ & $* * *$ & $* * *$ & $* * *$ & $* * *$ & $* * *$ & $* * *$ & $* * *$ \\
\hline Smokes & $\begin{array}{c}73 \\
{[0.088]}\end{array}$ & $\begin{array}{c}36 \\
(0.493)\end{array}$ & $* * *$ & $\begin{array}{c}7 \\
(0.096)\end{array}$ & $\begin{array}{c}4 \\
(0.055)\end{array}$ & $\begin{array}{c}8 \\
(0.110)\end{array}$ & $\begin{array}{c}7 \\
(0.096)\end{array}$ & $\begin{array}{c}16 \\
(0.219)\end{array}$ \\
\hline $\mathrm{AD}$ & $\begin{array}{c}33 \\
{[0.040]}\end{array}$ & $\begin{array}{c}5 \\
(0.152)\end{array}$ & $\begin{array}{c}7 \\
(0.212)\end{array}$ & $* * *$ & $\begin{array}{c}14 \\
(0.424)\end{array}$ & $\begin{array}{c}33 \\
(1.000)\end{array}$ & $\begin{array}{c}3 \\
(0.091)\end{array}$ & $\begin{array}{c}15 \\
(0.455)\end{array}$ \\
\hline HD & $\begin{array}{c}30 \\
{[0.036]}\end{array}$ & $\begin{array}{c}8 \\
(0.267)\end{array}$ & $4(0.133)$ & $\begin{array}{c}14 \\
(0.467)\end{array}$ & $* * *$ & $\begin{array}{c}30 \\
(1.000)\end{array}$ & $\begin{array}{c}2 \\
(0.067)\end{array}$ & $\begin{array}{c}10 \\
(0.333)\end{array}$ \\
\hline ADHD & $\begin{array}{c}49 \\
{[0.059]}\end{array}$ & $\begin{array}{c}25 \\
(0.510)\end{array}$ & $8(0.163)$ & $\begin{array}{c}33 \\
(0.673)\end{array}$ & $\begin{array}{c}29 \\
(0.592)\end{array}$ & $* * *$ & $\begin{array}{c}4 \\
(0.082)\end{array}$ & $\begin{array}{c}19 \\
(0.388)\end{array}$ \\
\hline Obese & $\begin{array}{c}68 \\
{[0.082]}\end{array}$ & $\begin{array}{c}39 \\
(0.574)\end{array}$ & $7(0.103)$ & $\begin{array}{c}3 \\
(0.044)\end{array}$ & $\begin{array}{c}2 \\
(0.029)\end{array}$ & $\begin{array}{c}4 \\
(0.059)\end{array}$ & $* * *$ & $\begin{array}{c}17 \\
(0.250)\end{array}$ \\
\hline Depression & $\begin{array}{c}140 \\
{[0.168\}}\end{array}$ & $\begin{array}{c}93 \\
(0.664)\end{array}$ & $\begin{array}{c}16 \\
(0.114)\end{array}$ & $\begin{array}{c}15 \\
(0.107)\end{array}$ & $\begin{array}{c}10 \\
(0.071)\end{array}$ & $\begin{array}{c}19 \\
(0.136)\end{array}$ & $\begin{array}{c}17 \\
(0.121)\end{array}$ & $* * *$ \\
\hline \multicolumn{9}{|c|}{ Wave $4, \mathrm{~N}=863$} \\
\hline Nothing & $\begin{array}{c}477 \\
{[0.553]}\end{array}$ & $* * *$ & $* * *$ & $* * *$ & $* * *$ & $* * *$ & $* * *$ & $* * *$ \\
\hline Smokes & $\begin{array}{c}82 \\
{[0.095]}\end{array}$ & $\begin{array}{c}42 \\
(0.512)\end{array}$ & **** & $\begin{array}{c}9 \\
(0.110)\end{array}$ & $\begin{array}{c}5 \\
(0.061)\end{array}$ & $\begin{array}{c}10 \\
(0.122)\end{array}$ & $\begin{array}{c}10 \\
(0.122)\end{array}$ & $\begin{array}{c}21 \\
(0.256)\end{array}$ \\
\hline $\mathrm{AD}$ & $\begin{array}{c}37 \\
{[0.043]}\end{array}$ & $\begin{array}{c}7 \\
(0.189)\end{array}$ & $\begin{array}{c}9 \\
(0.243)\end{array}$ & $* * *$ & $\begin{array}{c}17 \\
(0.459)\end{array}$ & $\begin{array}{c}37 \\
(1.000)\end{array}$ & $\begin{array}{c}4 \\
(0.108)\end{array}$ & $\begin{array}{c}15 \\
(0.405)\end{array}$ \\
\hline HD & $\begin{array}{c}34 \\
{[0.039]}\end{array}$ & $\begin{array}{c}9 \\
(0.265)\end{array}$ & $\begin{array}{c}5 \\
(0.147)\end{array}$ & $\begin{array}{c}17 \\
(0.5)\end{array}$ & $* * *$ & $\begin{array}{c}34 \\
(1.000)\end{array}$ & $\begin{array}{c}3 \\
(0.088)\end{array}$ & $\begin{array}{c}9 \\
(0.265)\end{array}$ \\
\hline ADHD & $\begin{array}{c}54 \\
{[0.063]}\end{array}$ & $\begin{array}{c}25 \\
(0.463)\end{array}$ & $\begin{array}{c}10 \\
(0.185)\end{array}$ & $\begin{array}{c}37 \\
(0.685)\end{array}$ & $\begin{array}{c}33 \\
(0.611)\end{array}$ & $* * *$ & $\begin{array}{c}5 \\
(0.093)\end{array}$ & $\begin{array}{c}19 \\
(0.352)\end{array}$ \\
\hline Obese & $\begin{array}{c}70 \\
{[0.081]}\end{array}$ & $\begin{array}{c}34 \\
(0.486)\end{array}$ & $\begin{array}{c}10 \\
(0.143)\end{array}$ & $\begin{array}{c}4 \\
(0.057)\end{array}$ & $\begin{array}{c}3 \\
(0.043)\end{array}$ & $\begin{array}{c}5 \\
(0.071)\end{array}$ & $* * *$ & $\begin{array}{c}17 \\
(0.243)\end{array}$ \\
\hline Depression & $\begin{array}{c}146 \\
{[0.169]}\end{array}$ & $\begin{array}{c}96 \\
(0.656)\end{array}$ & $\begin{array}{c}21 \\
(0.144)\end{array}$ & $\begin{array}{c}15 \\
(0.103)\end{array}$ & $\begin{array}{c}9 \\
(0.062)\end{array}$ & $\begin{array}{c}19 \\
(0.130)\end{array}$ & $\begin{array}{c}17 \\
(0.116)\end{array}$ & $* * *$ \\
\hline \multicolumn{9}{|c|}{ Wave $5, N=879$} \\
\hline Nothing & $\begin{array}{c}483 \\
{[0.595]}\end{array}$ & $* * *$ & $* * *$ & $* * *$ & $* * *$ & $* * *$ & $* * *$ & $* * *$ \\
\hline Smokes & $\begin{array}{c}129 \\
{[0.147]}\end{array}$ & $\begin{array}{c}60 \\
(0.465)\end{array}$ & $* * *$ & $\begin{array}{c}15 \\
(0.116)\end{array}$ & $\begin{array}{c}11 \\
(0.085)\end{array}$ & $\begin{array}{c}18 \\
(0.14)\end{array}$ & $\begin{array}{c}15 \\
(0.116)\end{array}$ & $\begin{array}{c}20 \\
(0.155)\end{array}$ \\
\hline $\mathrm{AD}$ & $\begin{array}{c}38 \\
{[0.043]}\end{array}$ & $\begin{array}{c}8 \\
(0.211)\end{array}$ & $\begin{array}{c}15 \\
(0.395)\end{array}$ & $* * *$ & $\begin{array}{c}18 \\
(0.474)\end{array}$ & $\begin{array}{c}38 \\
(1.000)\end{array}$ & $\begin{array}{c}4 \\
(0.105)\end{array}$ & $\begin{array}{c}10 \\
(0.263)\end{array}$ \\
\hline HD & $\begin{array}{c}36 \\
{[0.041]}\end{array}$ & $\begin{array}{c}8 \\
(0.222)\end{array}$ & $\begin{array}{c}11 \\
(0.306)\end{array}$ & $\begin{array}{c}18 \\
(0.500)\end{array}$ & $* * *$ & $\begin{array}{c}36 \\
(1.000)\end{array}$ & $\begin{array}{c}3 \\
(0.083)\end{array}$ & $\begin{array}{c}9 \\
(0.250)\end{array}$ \\
\hline ADHD & $\begin{array}{c}56 \\
{[0.064]}\end{array}$ & $\begin{array}{c}30 \\
(0.536)\end{array}$ & $\begin{array}{c}18 \\
(0.321)\end{array}$ & $\begin{array}{c}38 \\
(0.679)\end{array}$ & $\begin{array}{c}36 \\
(0.643)\end{array}$ & $* * *$ & $\begin{array}{c}5 \\
(0.089)\end{array}$ & $\begin{array}{c}15 \\
(0.268)\end{array}$ \\
\hline Obese & $\begin{array}{c}67 \\
{[0.076]}\end{array}$ & $\begin{array}{c}28 \\
(0.418)\end{array}$ & $\begin{array}{c}15 \\
(0.224)\end{array}$ & $\begin{array}{c}4 \\
(0.06)\end{array}$ & $\begin{array}{c}3 \\
(0.045)\end{array}$ & $\begin{array}{c}5 \\
(0.075)\end{array}$ & $* * *$ & $\begin{array}{c}10 \\
(0.149)\end{array}$ \\
\hline Depression & $\begin{array}{c}107 \\
{[0.122]}\end{array}$ & $\begin{array}{c}66 \\
(0.617)\end{array}$ & $\begin{array}{c}20 \\
(0.187)\end{array}$ & $\begin{array}{c}10 \\
(0.093)\end{array}$ & $\begin{array}{c}9 \\
(0.084)\end{array}$ & $\begin{array}{c}15 \\
(0.140)\end{array}$ & $\begin{array}{c}10 \\
(0.093)\end{array}$ & $* * *$ \\
\hline
\end{tabular}

Note: Each cell contains the number of individuals diagnosed with the respective row and column combination. The conditional frequency of dual diagnoses is presented in round parentheses. The marginal probability of being diagnosed with each outcome is presented in square parentheses.

\footnotetext{
${ }^{1}$ For ADHD nothing else excludes AD and HD.
} 
Table 5: Ordinary Least Squares Estimates of the Achievement Equation

\begin{tabular}{|c|c|c|c|c|c|c|}
\hline & Full Sample & $\begin{array}{l}\text { Females } \\
\text { Only }\end{array}$ & $\begin{array}{l}\text { Males } \\
\text { Only }\end{array}$ & Full Sample & $\begin{array}{l}\text { Females } \\
\text { Only }\end{array}$ & $\begin{array}{l}\text { Males } \\
\text { Only }\end{array}$ \\
\hline ADHD & $\begin{array}{c}-0.198^{* *} \\
(0.094)\end{array}$ & $\begin{array}{c}-0.154^{*} \\
(0.041)\end{array}$ & $\begin{array}{c}-0.241^{* * *} \\
(0.123)\end{array}$ & N/A & N/A & N/A \\
\hline $\mathrm{AD}$ & N/A & N/A & N/A & $\begin{array}{c}-0.431 * * \\
(0.172)\end{array}$ & $\begin{array}{c}-0.350^{* *} \\
(0.157)\end{array}$ & $\begin{array}{c}-0.493 * * \\
(0.195)\end{array}$ \\
\hline $\mathrm{HD}$ & N/A & N/A & N/A & $\begin{array}{l}0.158^{*} \\
(0.033)\end{array}$ & $\begin{array}{c}0.120 \\
(0.071)\end{array}$ & $\begin{array}{c}0.177 * * * \\
(0.096)\end{array}$ \\
\hline Depression & $\begin{array}{l}-0.143^{*} \\
(0.022)\end{array}$ & $\begin{array}{l}-0.097^{*} \\
(0.031)\end{array}$ & $\begin{array}{l}-0.191 * \\
(0.047)\end{array}$ & $\begin{array}{l}-0.135^{*} \\
(0.021)\end{array}$ & $\begin{array}{l}-0.094^{*} \\
(0.027)\end{array}$ & $\begin{array}{c}-0.180^{*} \\
(0.049)\end{array}$ \\
\hline Obesity & $\begin{array}{l}-0.371^{*} \\
(0.051)\end{array}$ & $\begin{array}{l}-0.529 * \\
(0.074)\end{array}$ & $\begin{array}{l}-0.204^{*} \\
(0.051)\end{array}$ & $\begin{array}{l}-0.370^{*} \\
(0.050)\end{array}$ & $\begin{array}{c}-0.533^{* *} \\
(0.065)\end{array}$ & $\begin{array}{l}-0.199^{*} \\
(0.055)\end{array}$ \\
\hline $\begin{array}{l}\text { Smoker in } \\
\text { Home }\end{array}$ & $\begin{array}{l}-0.199 * \\
(0.022)\end{array}$ & $\begin{array}{l}-0.135 * \\
(0.034)\end{array}$ & $\begin{array}{c}-0.274 * \\
(0.039)\end{array}$ & $\begin{array}{l}-0.195 * \\
(0.021)\end{array}$ & $\begin{array}{l}-0.135^{*} \\
(0.034)\end{array}$ & $\begin{array}{c}-0.265^{*} \\
(0.037)\end{array}$ \\
\hline Age & $\begin{array}{c}0.856^{* *} \\
(0.381)\end{array}$ & $\begin{array}{c}0.754 * * \\
(0.367)\end{array}$ & $\begin{array}{c}0.918 \\
(0.563)\end{array}$ & $\begin{array}{c}0.856^{* *} \\
(0.357)\end{array}$ & $\begin{array}{c}0.745^{* *} \\
(0.364)\end{array}$ & $\begin{array}{c}0.917 * * * \\
(0.545)\end{array}$ \\
\hline Age Squared & $\begin{array}{c}-0.027^{* *} \\
(0.012)\end{array}$ & $\begin{array}{c}-0.022 * * * \\
(0.013)\end{array}$ & $\begin{array}{c}-0.030 * * * \\
(0.018)\end{array}$ & $\begin{array}{c}-0.027^{* *} \\
(0.012)\end{array}$ & $\begin{array}{c}-0.022 * * * \\
(0.013)\end{array}$ & $\begin{array}{c}-0.030^{* * *} \\
(0.018)\end{array}$ \\
\hline Black & $\begin{array}{c}-0.313^{*} \\
(0.034)\end{array}$ & $\begin{array}{c}-0.276^{*} \\
(0.060)\end{array}$ & $\begin{array}{c}-0.345^{*} \\
(0.032)\end{array}$ & $\begin{array}{l}-0.318^{*} \\
(0.033)\end{array}$ & $\begin{array}{l}-0.283^{*} \\
(0.062)\end{array}$ & $\begin{array}{c}-0.346^{*} \\
(0.033)\end{array}$ \\
\hline Hispanic & $\begin{array}{l}-0.266^{*} \\
(0.034)\end{array}$ & $\begin{array}{c}-0.253^{* * * *} \\
(0.102)\end{array}$ & $\begin{array}{c}-0.250^{* *} \\
(0.127)\end{array}$ & $\begin{array}{l}-0.255^{*} \\
(0.084)\end{array}$ & $\begin{array}{c}-0.235^{* *} \\
(0.105)\end{array}$ & $\begin{array}{l}-0.244 \\
(0.130)\end{array}$ \\
\hline Asian & $\begin{array}{c}0.095 \\
(0.061)\end{array}$ & $\begin{array}{c}0.170^{* * *} \\
(0.092)\end{array}$ & $\begin{array}{c}-0.053 \\
(0.071)\end{array}$ & $\begin{array}{c}0.094 \\
(0.062)\end{array}$ & $\begin{array}{c}0.163 * * * \\
(0.094)\end{array}$ & $\begin{array}{l}-0.041 \\
(0.068)\end{array}$ \\
\hline Male & $\begin{array}{l}-0.255^{*} \\
(0.051)\end{array}$ & $\mathrm{N} / \mathrm{A}$ & N/A & $\begin{array}{l}-0.249 * \\
(0.055)\end{array}$ & N/A & $\mathrm{N} / \mathrm{A}$ \\
\hline Constant & $\begin{array}{l}-3.234 \\
(2.950)\end{array}$ & $\begin{array}{l}-2.986 \\
(2.520)\end{array}$ & $\begin{array}{l}-3.636 \\
(4.251)\end{array}$ & $\begin{array}{l}-3.216 \\
(2.713)\end{array}$ & $\begin{array}{l}-2.912 \\
(2.456)\end{array}$ & $\begin{array}{l}-3.587 \\
(4.139)\end{array}$ \\
\hline $\mathrm{N}$ & 2576 & 1366 & 1210 & 2576 & 1366 & 1210 \\
\hline R squared & 0.19 & 0.21 & 0.14 & 0.20 & 0.21 & 0.16 \\
\hline
\end{tabular}

Note: Corrected standard errors in parentheses. Regressions include school and time period indicators. ${ }^{*},{ }^{* *},{ }^{* * *}$ denote statistical significance at $1 \%, 5 \%, 10 \%$ level respectively. 
Table 6: Summary Information on the Performance of the Instruments

\begin{tabular}{|l|c|l|l|c|c|c|}
\hline & Full Sample & $\begin{array}{l}\text { Females } \\
\text { Only }\end{array}$ & $\begin{array}{l}\text { Males } \\
\text { Only }\end{array}$ & Full Sample & $\begin{array}{l}\text { Females } \\
\text { Only }\end{array}$ & $\begin{array}{l}\text { Males } \\
\text { Only }\end{array}$ \\
\hline \multicolumn{7}{|c|}{ First Stage F statistics } \\
\hline ADHD & 9.51 & 8.12 & 7.25 & N/A & N/A & N/A \\
\hline AD & N/A & N/A & N/A & 13.80 & 10.25 & 10.88 \\
\hline HD & N/A & N/A & N/A & 9.37 & 12.83 & 7.32 \\
\hline Depression & 6.95 & 5.78 & 6.55 & 6.95 & 5.78 & 6.55 \\
\hline Obesity & 7.43 & 12.55 & 11.39 & 7.43 & 12.55 & 11.39 \\
\hline Smoking & 6.38 & 9.83 & 8.81 & 6.38 & 9.83 & 8.81 \\
\hline \multicolumn{7}{|c|}{ P-values from Overidentification Tests } \\
\hline ADHD & 0.553 & 0.420 & 0.236 & N/A & N/A & N/A \\
\hline AD & N/A & N/A & 0.817 & 0.842 & 0982 & 0.440 \\
\hline HD & N/A & N/A & N/A & 0.845 & 0.812 & 0.266 \\
\hline Depression & 0.773 & 0.822 & 0.465 & 0.773 & 0.822 & 0.465 \\
\hline Obesity & 0.216 & 0.232 & 0.817 & 0.216 & 0.232 & 0.817 \\
\hline Achievement & 0.267 & 0.874 & 0.421 & 0.524 & 0.617 & 0.293 \\
\hline
\end{tabular}

Note: First stage F statistics is computed from a joint test of significance of the full set of genetic instruments from individual first stage regressions that also include the full set of control variables included in the second stage. In each case, the Null is rejected at the $1 \%$ level. P-values are computed from Sargan tests of the joint null hypothesis that the excluded instruments are valid instruments. 
Table 7: Two Stage Least Squares Estimates of the Achievement Equation

\begin{tabular}{|l|c|c|c|c|c|c|}
\hline & $\begin{array}{l}\text { Full } \\
\text { Sample }\end{array}$ & $\begin{array}{l}\text { Females } \\
\text { Only }\end{array}$ & Males Only & $\begin{array}{l}\text { Full } \\
\text { Sample }\end{array}$ & $\begin{array}{l}\text { Females } \\
\text { Only }\end{array}$ & Males Only \\
\hline ADHD & 0.017 & -0.074 & 0.161 & N/A & N/A & N/A \\
& N/A & N/A & N/A & -0.644 & $-1.410^{* *}$ & -0.036 \\
& & & & $(0.487)$ & $(0.661)$ & $(0.421)$ \\
\hline AD & N/A & N/A & N/A & $\begin{array}{c}1.297^{* * *} \\
(0.718)\end{array}$ & $\begin{array}{c}1.306^{* * *} \\
(0.790)\end{array}$ & $\begin{array}{c}0.753 \\
(0.661)\end{array}$ \\
\hline Depression & $-0.574^{* *}$ & $-1.112^{*}$ & -0.127 & $-0.520^{* *}$ & $-0.822^{* *}$ & -0.237 \\
& $(0.238)$ & $(0.308)$ & $(0.246)$ & $(0.250)$ & $(0.331)$ & $(0.249)$ \\
\hline Obesity & -0.288 & -0.452 & 0.338 & $-0.634^{* *}$ & $-0.838^{* *}$ & 0.011 \\
& $(0.282)$ & $(0.275)$ & $(0.278)$ & $(0.294)$ & $(0.359)$ & $(0.301)$ \\
\hline Smoker in & $-0.194^{*}$ & $-0.094^{* *}$ & $-0.306^{*}$ & $-0.187^{*}$ & $-0.095^{* *}$ & $-0.296^{*}$ \\
Home & $(0.031)$ & $(0.043)$ & $(0.047)$ & $(0.034)$ & $(0.043)$ & $(0.048)$ \\
\hline Age & 0.691 & 0.378 & 0.761 & 0.663 & 0.611 & 0.626 \\
& $(0.547)$ & $(0.886)$ & $(0.799)$ & $(0.562)$ & $(0.868)$ & $(0.791)$ \\
\hline Age Squared & -0.022 & -0.011 & -0.025 & -0.021 & -0.018 & -0.021 \\
& $(0.016)$ & $(0.026)$ & $(0.024)$ & $(0.016)$ & $(0.025)$ & $(0.023)$ \\
\hline Black & $-0.323^{*}$ & $-0.367^{*}$ & $-0.342^{*}$ & $-0.319^{*}$ & $-0.372^{*}$ & $-0.321^{*}$ \\
& $(0.048)$ & $(0.061)$ & $(0.078)$ & $(0.049)$ & $(0.063)$ & $(0.076)$ \\
\hline Hispanic & $-0.259^{*}$ & -0.137 & $-0.234^{*}$ & $-0.224^{*}$ & -0.021 & -0.255 \\
& $(0.047)$ & $(0.094)$ & $(0.066)$ & $(0.054)$ & $(0.122)$ & $(0.067)$ \\
\hline Asian & $0.128^{*}$ & $0.225^{*}$ & -0.067 & $0.127^{*}$ & $0.150^{*}$ & -0.018 \\
& $(0.039)$ & $(0.061)$ & $(0.062)$ & $(0.041)$ & $(0.069)$ & $(0.069)$ \\
\hline $\mathrm{N}$ & 2576 & 1366 & 1210 & 2576 & 1366 & 1210 \\
\hline
\end{tabular}

Note: Corrected standard errors in parentheses. Regressions include school and time period indicators. ${ }^{*}, * *, * * *$ denote statistical significance at $1 \%, 5 \%, 10 \%$ level respectively. 
Table 8: Two Stage Least Squares Estimates of the Achievement Equation where Years of Smoking is Treated as Exogenous

\begin{tabular}{|l|c|l|c|c|c|c|}
\hline & Full Sample & $\begin{array}{l}\text { Females } \\
\text { Only }\end{array}$ & $\begin{array}{l}\text { Males } \\
\text { Only }\end{array}$ & Full Sample & $\begin{array}{l}\text { Females } \\
\text { Only }\end{array}$ & $\begin{array}{l}\text { Males } \\
\text { Only }\end{array}$ \\
\hline ADHD & $-0.959^{* *}$ & -0.630 & -0.138 & N/A & N/A & N/A \\
& $(0.414)$ & $(0.447)$ & $(0.422)$ & & & \\
\hline AD & N/A & N/A & N/A & -1.382 & $-3.760^{* *}$ & -0.441 \\
& N/A & N/A & N/A & 1.101 & $3.7829)$ & $(0.727)$ \\
\hline HD & & & & $(0.993)$ & $(2.488)$ & $\begin{array}{c}1.689 \\
(1.413)\end{array}$ \\
\hline Depression & $-1.297^{*}$ & $-1.251^{*}$ & $-0.857^{* *}$ & -1.304 & -0.962 & $-1.456^{*}$ \\
& $(0.334)$ & $(0.429)$ & $(0.347)$ & $(0.298)$ & $(0.756)$ & $(0.510)$ \\
\hline Obesity & -0.158 & $-0.601^{* * *}$ & $0.774^{* * *}$ & $-0.912^{*}$ & $-2.080^{* * *}$ & 0.833 \\
& $(0.408)$ & $(0.351)$ & $(0.429)$ & $(0.353)$ & $(1.095)$ & $(0.604)$ \\
\hline Smoker in & $-0.123^{*}$ & -0.062 & $-0.280^{* *}$ & $-0.113^{*}$ & -0.045 & $-0.268^{*}$ \\
Home & $(0.041)$ & $(0.048)$ & $(0.053)$ & $(0.034)$ & $(0.074)$ & $(0.070)$ \\
\hline Age & 0.787 & 0.458 & 0.774 & 0.734 & 1.051 & 0.319 \\
& $(0.664)$ & $(0.969)$ & $(0.842)$ & $(0.566)$ & $(1.350)$ & $(0.979)$ \\
\hline Age Squared & -0.024 & -0.014 & -0.024 & -0.023 & -0.030 & -0.010 \\
& $(0.019)$ & $(0.028)$ & $(0.025)$ & $(0.017)$ & $(0.039)$ & $(0.029)$ \\
\hline Black & $-0.389^{*}$ & $-0.386^{*}$ & $-0.348^{*}$ & $-0.371^{*}$ & $-0.429^{* *}$ & $-0.299^{*}$ \\
& $(0.061)$ & $(0.070)$ & $(0.096)$ & $(0.049)$ & $(0.107)$ & $(0.109)$ \\
\hline Hispanic & $-0.228^{*}$ & -0.070 & $-0.270^{*}$ & $-0.153^{*}$ & 0.345 & $-0.315^{*}$ \\
& $(0.059)$ & $(0.107)$ & $(0.076)$ & $(0.056)$ & $(0.287)$ & $(0.093)$ \\
\hline Asian & $0.164^{*}$ & $0.219^{*}$ & -0.025 & $0.157^{*}$ & 0.010 & 0.104 \\
& $(0.055)$ & $(0.068)$ & $(0.074)$ & $(0.042)$ & $(0.160)$ & $(0.117)$ \\
\hline Male & $-0.267^{*}$ & N/A & N/A & $-0.260^{*}$ & N/A & N/A \\
& $(0.031)$ & & & $(0.026)$ & & \\
\hline Constant & -2.751 & -0.184 & -2.816 & -2.153 & -5.355 & 0.860 \\
& $(5.686)$ & $(8.342)$ & $(7.180)$ & $(4.835)$ & $(11.649)$ & $(8.364)$ \\
\hline N & 2576 & 1366 & 1210 & 2576 & 1366 & 1210 \\
\hline
\end{tabular}

Note: Corrected standard errors in parentheses. Regressions include school and time period indicators. ${ }^{*},{ }^{* *},{ }^{* * *}$ denote statistical significance at $1 \%, 5 \%, 10 \%$ level respectively. 
Table 9: Two Stage Least Squares Estimates of the Achievement Equation Including A Subset of Health Outcomes

\begin{tabular}{|l|c|c|c|}
\hline $\begin{array}{l}\text { Include health } \\
\text { behaviors }\end{array}$ & Full Sample & \multicolumn{1}{l|}{ Girls } & \multicolumn{1}{l|}{ Boys } \\
\hline ADHD & $\begin{array}{l}-0.351 \\
(0.319)\end{array}$ & $\begin{array}{l}-0.319 \\
(0.359)\end{array}$ & $\begin{array}{c}0.284 \\
(0.452)\end{array}$ \\
\hline $\mathrm{AD}$ & $\begin{array}{c}1.392^{* * *} \\
(0.669)\end{array}$ & $\begin{array}{l}0.648 \\
(0.633)\end{array}$ & 0.615 \\
& $-1.966^{* * *}$ & -1.040 & $0.546)$ \\
\hline $\mathrm{HD}$ & $(1.183)$ & $(0.609)$ & $(0.911)$ \\
\hline $\mathrm{AD}$ & 0.529 & -0.124 & 0.766 \\
& $(0.304)$ & $(0.400)$ & $(0.383)$ \\
\hline HD & -0.144 & -0.330 & 0.972 \\
& $(0.517)$ & $(0.445)$ & $(0.766)$ \\
\hline Depression & $-0.713^{* *}$ & $-1.250 *$ & -0.032 \\
& $(0.302)$ & $(0.455)$ & $(0.391)$ \\
\hline Obesity & -0.331 & -0.352 & 1.067 \\
& $(0.329)$ & $(0.235)$ & $(0.738)$ \\
\hline Observations & 2576 & 1366 & 1210 \\
\hline
\end{tabular}

Note: Corrected standard errors in parentheses. Each cell of the table corresponds to a separate regression. The dependent variable of the regression differs by row. Columns reflect different samples. Regressions include the non-health inputs in Table 7, school and time period indicators. $*, * *, * * *$ denote statistical significance at 1\%,5\%, 10\% level respectively. 
Appendix Table 1: Ordinary Least Squares Estimates of the Cigarette Smoker Equation

\begin{tabular}{|l|c|c|c|c|c|c|}
\hline & Full Sample & Females Only & Males Only & Full Sample & Females Only & Males Only \\
\hline ADHD & 0.092 & 0.139 & 0.051 & N/A & N/A & N/A \\
& $(0.056)$ & $(0.077)$ & $(0.061)$ & & & \\
\hline AD & N/A & N/A & N/A & $0.155^{* * *}$ & $0.280^{*}$ & 0.096 \\
& & & & $(0.060)$ & $(0.082)$ & $(0.064)$ \\
\hline HD & N/A & N/A & N/A & 0.020 & 0.042 & 0.006 \\
& & & & $(0.034)$ & $(0.098)$ & $(0.074)$ \\
\hline Depression & 0.043 & -0.001 & 0.096 & 0.039 & -0.008 & 0.093 \\
& $(0.029)$ & $(0.052)$ & $(0.071)$ & $(0.029)$ & $(0.050)$ & $(0.071)$ \\
\hline Obesity & 0.019 & 0.104 & -0.060 & 0.019 & 0.104 & -0.060 \\
& $(0.075)$ & $(0.136)$ & $(0.071)$ & $(0.074)$ & $(0.132)$ & $(0.071)$ \\
\hline Smoker in & $0.121^{* * *}$ & $0.198^{* * *}$ & 0.019 & $0.119^{* * *}$ & $0.195^{* *}$ & 0.017 \\
Home & $(0.063)$ & $(0.092)$ & $(0.052)$ & $(0.064)$ & $(0.092)$ & $(0.052)$ \\
\hline Age & $-0.963^{* *}$ & -0.610 & $-1.031^{*}$ & $-0.971^{*}$ & $-0.613^{* * *}$ & $-1.038^{* *}$ \\
& $(0.280)$ & $(0.309)$ & $(0.484)$ & $(0.281)$ & $(0.305)$ & $(0.488)$ \\
\hline Age Squared & $0.030^{* *}$ & 0.020 & $0.032^{*}$ & $0.030^{*}$ & 0.020 & $0.032^{* *}$ \\
& $(0.009)$ & $(0.011)$ & $(0.015)$ & $(0.009)$ & $(0.011)$ & $(0.015)$ \\
\hline Black & -0.029 & 0.003 & -0.074 & -0.027 & 0.008 & -0.073 \\
& $(0.060)$ & $(0.065)$ & $(0.106)$ & $(0.061)$ & $(0.067)$ & $(0.106)$ \\
\hline Hispanic & $-0.074^{* * *}$ & -0.002 & $-0.167 *$ & $-0.079^{* *}$ & -0.014 & $-0.169^{*}$ \\
& $(0.040)$ & $(0.071)$ & $(0.054)$ & $(0.038)$ & $(0.074)$ & $(0.053)$ \\
\hline Asian & $-0.071^{* * *}$ & -0.065 & $-0.083^{* * *}$ & $-0.070^{* * *}$ & -0.061 & $-0.084^{* * *}$ \\
& $(0.029)$ & $(0.056)$ & $(0.037)$ & $(0.029)$ & $(0.057)$ & $(0.036)$ \\
\hline Male & 0.028 & $\mathrm{~N} / \mathrm{A}$ & $\mathrm{N} / \mathrm{A}$ & 0.026 & $\mathrm{~N} / \mathrm{A}$ & $\mathrm{N} / \mathrm{A}$ \\
& $(0.032)$ & & & $(0.034)$ & & \\
\hline Constant & $7.790^{* *}$ & $4.695^{* * *}$ & 8.386 & $7.847^{*}$ & $4.732^{* * *}$ & 8.436 \\
& $(2.232)$ & $(2.060)$ & $(3.948)$ & $(2.253)$ & $(2.078)$ & $(3.990)$ \\
\hline $\mathrm{N}$ & 2576 & 1366 & 1210 & 2576 & 1366 & 1210 \\
\hline R squared & 0.08 & 0.11 & 0.11 & 0.08 & 0.12 & 0.12 \\
\hline
\end{tabular}

Note: Corrected standard errors in parentheses. Regressions include school and time period indicators. ${ }^{*},{ }^{* *},{ }^{* * *}$ denote statistical significance at $1 \%, 5 \%, 10 \%$ level respectively. 
Appendix Table 2: Summary Statistics on GPA Performance by Health Disorder and Health Behavior

\begin{tabular}{|c|c|c|c|}
\hline & Grade 10 & Grade 11 & Grade 12 \\
\hline Smokers & $\begin{array}{c}2.673 \\
(0.661) \\
\end{array}$ & $\begin{array}{c}2.626 \\
(0.715) \\
\end{array}$ & $\begin{array}{c}2.847 \\
(0.688) \\
\end{array}$ \\
\hline Non Smokers & $\begin{array}{c}3.233 \\
(0.532)\end{array}$ & $\begin{array}{c}3.202 \\
(0.557)\end{array}$ & $\begin{array}{c}3.232 \\
(0.529)\end{array}$ \\
\hline $\begin{array}{l}\text { T-statistic for Differences in } \\
\text { Mean GPA by Smoking Status }\end{array}$ & $8.388 *$ & $8.662 *$ & $7.278^{*}$ \\
\hline Depression Diagnosis & $\begin{array}{c}3.035 \\
(0.617)\end{array}$ & $\begin{array}{c}3.003 \\
(0.647)\end{array}$ & $\begin{array}{c}3.025 \\
(0.665)\end{array}$ \\
\hline No depression Diagnosis & $\begin{array}{c}3.213 \\
(0.552) \\
\end{array}$ & $\begin{array}{c}3.177 \\
(0.583)\end{array}$ & $\begin{array}{c}3.197 \\
(0.554)\end{array}$ \\
\hline $\begin{array}{l}\text { T-statistic for Differences in } \\
\text { Mean GPA by Depression Status }\end{array}$ & $3.416^{*}$ & $3.224^{*}$ & $2.921^{*}$ \\
\hline Obese & $\begin{array}{c}2.830 \\
(0.620)\end{array}$ & $\begin{array}{c}2.699 \\
(0.729) \\
\end{array}$ & $\begin{array}{c}2.788 \\
(0.623) \\
\end{array}$ \\
\hline Non Obese (BMI <30) & $\begin{array}{c}3.215 \\
(0.552)\end{array}$ & $\begin{array}{c}3.187 \\
(0.568)\end{array}$ & $\begin{array}{c}3.208 \\
(0.555)\end{array}$ \\
\hline $\begin{array}{l}\text { T-statistic for Differences in } \\
\text { Mean GPA by Obesity Status }\end{array}$ & $5.453^{*}$ & $6.713^{*}$ & $5.883^{*}$ \\
\hline ADHD Diagnosis & $\begin{array}{c}2.929 \\
(0.694)\end{array}$ & $\begin{array}{c}2.919 \\
(0.685)\end{array}$ & $\begin{array}{c}2.919 \\
(0.697) \\
\end{array}$ \\
\hline No ADHD Diagnosis & $\begin{array}{c}3.200 \\
(0.555)\end{array}$ & $\begin{array}{c}3.163 \\
(0.589)\end{array}$ & $\begin{array}{c}3.193 \\
(0.558)\end{array}$ \\
\hline $\begin{array}{l}\text { T-statistic for Differences in } \\
\text { Mean GPA by ADHD Diagnosis }\end{array}$ & $3.263^{*}$ & $2.911 *$ & $3.492 *$ \\
\hline AD Diagnosis & $\begin{array}{c}2.714 \\
(0.703)\end{array}$ & $\begin{array}{c}2.733 \\
(0.718)\end{array}$ & $\begin{array}{c}2.754 \\
(0.742)\end{array}$ \\
\hline No AD Diagnosis & $\begin{array}{c}3.203 \\
(0.553) \\
\end{array}$ & $\begin{array}{c}3.166 \\
(0.585) \\
\end{array}$ & $\begin{array}{c}3.195 \\
(0.555) \\
\end{array}$ \\
\hline $\begin{array}{l}\text { T-statistic for Differences in } \\
\text { Mean GPA by AD Diagnosis }\end{array}$ & $4.921 *$ & $4.357 *$ & $4.713^{*}$ \\
\hline HD Diagnosis & $\begin{array}{c}3.155 \\
(0.527) \\
\end{array}$ & $\begin{array}{c}3.054 \\
(0.587) \\
\end{array}$ & $\begin{array}{c}3.047 \\
(0.630)\end{array}$ \\
\hline No HD Diagnosis & $\begin{array}{c}3.185 \\
(0.569) \\
\end{array}$ & $\begin{array}{c}3.151 \\
(0.598)\end{array}$ & $\begin{array}{c}3.181 \\
(0.568) \\
\end{array}$ \\
\hline $\begin{array}{l}\text { T-statistic for Differences in } \\
\text { Mean GPA by HD Diagnosis }\end{array}$ & 0.285 & 0.937 & 1.379 \\
\hline
\end{tabular}

Note: Most cells present the mean GPA and standard deviations in parentheses for individuals by health category. ${ }^{*}, * *, * * *$ denote statistically significant differences in mean GPA by health outcome at the 1\%, 5\%, $10 \%$ level respectively. 
Appendix Table 3: Two Stage Least Squares Estimates of the Achievement Equation by Subsample with Alternative Preferred instrument Sets

\begin{tabular}{|l|c|c|c|c|}
\hline & Females Only & Males Only & Females Only & Males Only \\
\hline ADHD & -0.222 & 0.255 & N/A & N/A \\
& $(0.350)$ & $(0.311)$ & -0.036 \\
AD & N/A & N/A & $-1.092^{* *}$ & $(0.541)$ \\
\hline HD & N/A & N/A & 0.580 & $0.438)$ \\
& & & $(0.421)$ & $(0.576)$ \\
\hline Depression & $-1.296^{*}$ & -0.207 & $-1.132^{*}$ & -0.199 \\
& $(0.349)$ & $(0.316)$ & $(0.324)$ & $(0.321)$ \\
\hline Obesity & -0.385 & 0.166 & $-0.708^{*}$ & 0.055 \\
& $(0.237)$ & $(0.311)$ & $(0.257)$ & $(0.351)$ \\
\hline Smoker in & -0.057 & $-0.246^{*}$ & -0.052 & $-0.237^{*}$ \\
Home & $(0.052)$ & $(0.048)$ & $(0.051)$ & $(0.048)$ \\
\hline Age & 0.291 & 0.634 & 0.490 & 0.587 \\
& $(0.959)$ & $(0.740)$ & $(0.924)$ & $(0.740)$ \\
\hline Age & -0.009 & -0.021 & -0.015 & -0.020 \\
Squared & $(0.028)$ & $(0.022)$ & $(0.027)$ & $(0.022)$ \\
\hline Black & $-0.397^{*}$ & $-0.324^{*}$ & $-0.383^{*}$ & $-0.321^{*}$ \\
& $(0.080)$ & $(0.075)$ & $(0.077)$ & $(0.074)$ \\
\hline Hispanic & -0.123 & $-0.263^{*}$ & -0.028 & $-0.274^{*}$ \\
& $(0.085)$ & $(0.060)$ & $(0.101)$ & $(0.060)$ \\
\hline Asian & $0.237^{*}$ & -0.054 & $0.183^{*}$ & -0.017 \\
& $(0.062)$ & $(0.068)$ & $(0.063)$ & $(0.073)$ \\
\hline N & 1366 & 1210 & 1366 & 1210 \\
\hline Note: Corre & & & \\
\hline
\end{tabular}

Note: Corrected standard errors in parentheses. Regressions include school and time period indicators. *, **, *** denote statistical significance at 1\%, 5\%, 10\% level respectively. 
Appendix Table 4: Three Stage Least Squares Estimates of the Achievement Equation

\begin{tabular}{|c|c|c|c|c|c|c|}
\hline & $\begin{array}{l}\text { Full } \\
\text { Sample }\end{array}$ & $\begin{array}{l}\text { Females } \\
\text { Only }\end{array}$ & $\begin{array}{l}\text { Males } \\
\text { Only }\end{array}$ & $\begin{array}{l}\text { Full } \\
\text { Sample }\end{array}$ & $\begin{array}{l}\text { Females } \\
\text { Only }\end{array}$ & $\begin{array}{l}\text { Males } \\
\text { Only }\end{array}$ \\
\hline ADHD & $\begin{array}{c}0.007 \\
(0.414)\end{array}$ & $\begin{array}{c}-0.107 \\
(0.449)\end{array}$ & $\begin{array}{c}0.139 \\
(0.464) \\
\end{array}$ & N/A & N/A & N/A \\
\hline $\mathrm{AD}$ & N/A & N/A & N/A & $\begin{array}{l}-0.451 \\
(0.571)\end{array}$ & $\begin{array}{c}-1.570 * * * \\
(0.980)\end{array}$ & $\begin{array}{l}-0.075 \\
(0.631)\end{array}$ \\
\hline HD & N/A & N/A & N/A & $\begin{array}{c}0.263 \\
(0.390)\end{array}$ & $\begin{array}{c}1.451 \\
(1.109)\end{array}$ & $\begin{array}{c}0.802 \\
(0.926)\end{array}$ \\
\hline Depression & $\begin{array}{l}-0.603 \\
(0.372)\end{array}$ & $\begin{array}{l}-1.135^{*} \\
(0.409)\end{array}$ & $\begin{array}{c}-0.112 \\
(0.418)\end{array}$ & $\begin{array}{l}-0.478 \\
(0.387)\end{array}$ & $\begin{array}{c}-0.768 * * * \\
(0.399)\end{array}$ & $\begin{array}{l}-0.244 \\
(0.430)\end{array}$ \\
\hline Obesity & $\begin{array}{l}-0.225 \\
(0.408)\end{array}$ & $\begin{array}{l}-0.407 \\
(0.355)\end{array}$ & $\begin{array}{c}0.228 \\
(0.446)\end{array}$ & $\begin{array}{l}-0.560 \\
(0.403)\end{array}$ & $\begin{array}{c}-0.871^{* * *} \\
(0.493)\end{array}$ & $\begin{array}{l}-0.059 \\
(0.452)\end{array}$ \\
\hline $\begin{array}{l}\text { Smoker in } \\
\text { Home }\end{array}$ & $\begin{array}{c}-0.080^{* *} \\
(0.038)\end{array}$ & $\begin{array}{l}-0.009 \\
(0.131)\end{array}$ & $\begin{array}{l}-0.177 \\
(0.140)\end{array}$ & $\begin{array}{l}-0.062 \\
(0.040)\end{array}$ & $\begin{array}{c}-0.002 \\
(0.048)\end{array}$ & $\begin{array}{r}-0.137^{*} \\
(0.054)\end{array}$ \\
\hline Age & $\begin{array}{c}0.037 \\
(0.358) \\
\end{array}$ & $\begin{array}{c}0.751 \\
(1.878)\end{array}$ & $\begin{array}{c}-0.585 \\
(1.391) \\
\end{array}$ & $\begin{array}{c}0.013 \\
(0.358) \\
\end{array}$ & $\begin{array}{c}-0.102 \\
(0.563)\end{array}$ & $\begin{array}{l}-0.040 \\
(0.483) \\
\end{array}$ \\
\hline Age Squared & $\begin{array}{l}-0.297 \\
(1.045)\end{array}$ & $\begin{array}{l}-0.026 \\
(0.050)\end{array}$ & $\begin{array}{c}-0.145^{*} \\
(0.051)\end{array}$ & $\begin{array}{l}-0.257 \\
(1.045)\end{array}$ & $\begin{array}{c}0.244 \\
(1.627)\end{array}$ & $\begin{array}{l}-0.228 \\
(1.414)\end{array}$ \\
\hline Black & $\begin{array}{c}-0.364^{*} \\
(0.069)\end{array}$ & $\begin{array}{l}-0.176 \\
(0.111)\end{array}$ & $\begin{array}{l}-0.271^{*} \\
(0.092)\end{array}$ & $\begin{array}{l}-0.358^{*} \\
(0.073)\end{array}$ & $\begin{array}{l}-0.392^{*} \\
(0.102)\end{array}$ & $\begin{array}{l}-0.388^{*} \\
(0.109)\end{array}$ \\
\hline Hispanic & $\begin{array}{l}-0.302^{*} \\
(0.063)\end{array}$ & $\begin{array}{c}0.223 \\
(0.081)\end{array}$ & $\begin{array}{l}-0.092 \\
(0.102)\end{array}$ & $\begin{array}{l}-0.276^{*} \\
(0.072)\end{array}$ & $\begin{array}{l}-0.055 \\
(0.162)\end{array}$ & $\begin{array}{c}-0.294^{*} \\
(0.093)\end{array}$ \\
\hline Asian & $\begin{array}{c}0.116^{* * *} \\
(0.061)\end{array}$ & $\begin{array}{l}-0.281 \\
(0.647)\end{array}$ & $\begin{array}{l}-0.084 \\
(0.477)\end{array}$ & $\begin{array}{c}0.108 \\
(0.065)\end{array}$ & $\begin{array}{l}0.132 * \\
(0.097)\end{array}$ & $\begin{array}{l}-0.036 \\
(0.114)\end{array}$ \\
\hline $\mathrm{N}$ & 2576 & 1366 & 1210 & 2576 & 1366 & 1210 \\
\hline
\end{tabular}

Note: Standard errors in parentheses. Regressions include school and time period indicators. $*, * *, * * *$ denote statistical significance at $1 \%, 5 \%, 10 \%$ level respectively. 
Appendix Table 5: Relationship Between Health Behaviors and Health Outcomes During Adolescence by Gender

\begin{tabular}{|c|c|c|c|c|c|c|c|}
\hline Behavior & $\begin{array}{l}\text { Total } \\
\text { Number }\end{array}$ & $\begin{array}{l}\text { Nothing } \\
\text { Else }\end{array}$ & $\begin{array}{l}\text { Also } \\
\text { Smokes }\end{array}$ & Also AD & Also HD & $\begin{array}{l}\text { Also } \\
\text { Obese }\end{array}$ & $\begin{array}{l}\text { Also } \\
\text { Depressed }\end{array}$ \\
\hline \multicolumn{8}{|c|}{ Wave $3, \mathrm{~N}=438$} \\
\hline Nothing & 231 & $* * *$ & $* * *$ & $* * *$ & $* * *$ & $* * *$ & $* * *$ \\
\hline Smokes & 33 & 13 & $* * *$ & 4 & 3 & 6 & 7 \\
\hline $\mathrm{AD}$ & 11 & 1 & 4 & $* * *$ & 4 & 1 & 7 \\
\hline HD & 13 & 3 & 3 & 4 & $* * *$ & 1 & 6 \\
\hline Obese & 34 & 19 & 6 & 1 & 1 & $* * *$ & 9 \\
\hline Depression & 81 & 59 & 7 & 7 & 6 & 9 & $* * *$ \\
\hline \multicolumn{8}{|c|}{ Wave $4, \mathrm{~N}=453$} \\
\hline Nothing & 237 & $* * *$ & $* * *$ & $* * *$ & $* * *$ & $* * *$ & $* * *$ \\
\hline Smokes & 35 & 8 & $* * *$ & 4 & 3 & 8 & 9 \\
\hline $\mathrm{AD}$ & 13 & 2 & 4 & $* * *$ & 4 & 2 & 7 \\
\hline $\mathrm{HD}$ & 15 & 5 & 3 & 4 & $* * *$ & 2 & 6 \\
\hline Obese & 36 & 17 & 8 & 2 & 2 & $* * *$ & 10 \\
\hline Depression & 88 & 64 & 9 & 7 & 6 & 10 & $* * *$ \\
\hline \multicolumn{8}{|c|}{ Wave $5, \mathrm{~N}=466$} \\
\hline Nothing & 243 & $* * *$ & $* * *$ & $* * *$ & $* * *$ & $* * *$ & $* * *$ \\
\hline Smokes & 64 & 30 & $* * *$ & 7 & 6 & 10 & 7 \\
\hline $\mathrm{AD}$ & 13 & 3 & 7 & $* * *$ & 6 & 2 & 3 \\
\hline HD & 15 & 4 & 6 & 6 & $* * *$ & 2 & 4 \\
\hline Obese & 35 & 11 & 10 & 2 & 2 & $* * *$ & 5 \\
\hline Depression & 56 & 41 & 7 & 3 & 4 & 5 & $* * *$ \\
\hline \multicolumn{8}{|c|}{ MALES } \\
\hline Behavior & $\begin{array}{l}\text { Total } \\
\text { Number }\end{array}$ & $\begin{array}{l}\text { Nothing } \\
\text { Else }\end{array}$ & $\begin{array}{l}\text { Also } \\
\text { Smokes }\end{array}$ & Also AD & Also HD & $\begin{array}{l}\text { Also } \\
\text { Obese }\end{array}$ & $\begin{array}{l}\text { Also } \\
\text { Depressed }\end{array}$ \\
\hline \multicolumn{8}{|c|}{ Wave $3, \mathrm{~N}=389$} \\
\hline Nothing & 240 & $* * *$ & $* * *$ & $* * *$ & $* * *$ & $* * *$ & $* * *$ \\
\hline Smokes & 39 & 23 & $* * *$ & 3 & 1 & 1 & 8 \\
\hline $\mathrm{AD}$ & 22 & 4 & 3 & $* * *$ & 10 & 1 & 8 \\
\hline HD & 16 & 5 & 1 & 10 & $* * *$ & 1 & 4 \\
\hline Obese & 34 & 22 & 1 & 2 & 1 & $* * *$ & 8 \\
\hline Depression & 58 & 34 & 8 & 8 & 4 & 8 & $* * *$ \\
\hline \multicolumn{8}{|c|}{ Wave $4, \mathrm{~N}=402$} \\
\hline Nothing & 240 & $* * *$ & $* * *$ & $* * *$ & $* * *$ & $* * *$ & $* * *$ \\
\hline Smokes & 46 & 27 & $* * *$ & 5 & 2 & 2 & 12 \\
\hline $\mathrm{AD}$ & 24 & 5 & 5 & $* * *$ & 13 & 2 & 7 \\
\hline $\mathrm{HD}$ & 18 & 4 & 2 & 13 & $* * *$ & 1 & 3 \\
\hline Obese & 34 & 20 & 2 & 2 & 1 & $* * *$ & 7 \\
\hline Depression & 58 & 32 & 12 & 7 & 3 & 7 & $* * *$ \\
\hline \multicolumn{8}{|c|}{ Wave $5, \mathrm{~N}=405$} \\
\hline Nothing & 240 & $* * *$ & $* * *$ & $* * *$ & $* * *$ & $* * *$ & $* * *$ \\
\hline Smokes & 62 & 30 & $* * *$ & 8 & 5 & 5 & 10 \\
\hline $\mathrm{AD}$ & 25 & 5 & 8 & $* * *$ & 12 & 2 & 7 \\
\hline HD & 20 & 4 & 5 & 12 & $* * *$ & 1 & 5 \\
\hline Obese & 32 & 17 & 5 & 2 & 1 & $* * *$ & 5 \\
\hline Depression & 51 & 25 & 10 & 7 & 5 & 5 & $* * *$ \\
\hline
\end{tabular}


Appendix Table 6: OLS and Two Stage Least Squares Estimates of the Impacts of Cigarette Smoking on Health Outcomes

\begin{tabular}{|c|c|c|c|c|c|c|}
\hline & $\begin{array}{l}\text { Full } \\
\text { Sample }\end{array}$ & $\begin{array}{l}\text { Females } \\
\text { Only }\end{array}$ & $\begin{array}{l}\text { Males } \\
\text { Only }\end{array}$ & $\begin{array}{l}\text { Full } \\
\text { Sample }\end{array}$ & $\begin{array}{l}\text { Females } \\
\text { Only }\end{array}$ & $\begin{array}{l}\text { Males } \\
\text { Only }\end{array}$ \\
\hline \multicolumn{7}{|c|}{ Two Stage Least Squares } \\
\hline $\mathrm{AD}$ & N/A & N/A & N/A & $\begin{array}{c}0.006 \\
(0.046)\end{array}$ & $\begin{array}{c}0.009 \\
(0.051)\end{array}$ & $\begin{array}{c}-0.009 \\
(0.051)\end{array}$ \\
\hline HD & N/A & N/A & N/A & $\begin{array}{c}-0.050 \\
(0.046)\end{array}$ & $\begin{array}{c}0.095 \\
(0.058)\end{array}$ & $\begin{array}{l}-0.111^{*} \\
(0.046)\end{array}$ \\
\hline ADHD & $\begin{array}{c}-0.092 \\
(0.060)\end{array}$ & $\begin{array}{c}0.092 \\
(0.086)\end{array}$ & $\begin{array}{c}-0.126 * \\
(0.063)\end{array}$ & N/A & N/A & $\mathrm{N} / \mathrm{A}$ \\
\hline Depressed & $\begin{array}{c}0.036 \\
(0.088)\end{array}$ & $\begin{array}{l}-0.126 \\
(0.129)\end{array}$ & $\begin{array}{c}0.052 \\
(0.076)\end{array}$ & $\begin{array}{c}0.028 \\
(0.086)\end{array}$ & $\begin{array}{l}-0.096 \\
(0.126)\end{array}$ & $\begin{array}{c}0.044 \\
(0.074)\end{array}$ \\
\hline Obese & $\begin{array}{l}-0.097 \\
(0.079)\end{array}$ & $\begin{array}{c}-0.126 \\
(0.129)\end{array}$ & $\begin{array}{c}-0.073 \\
(0.077)\end{array}$ & $\begin{array}{c}0.046 \\
(0.070)\end{array}$ & $\begin{array}{l}-0.053 \\
(0.090)\end{array}$ & $\begin{array}{c}-0.043 \\
(0.067)\end{array}$ \\
\hline \multicolumn{7}{|c|}{ OLS } \\
\hline $\mathrm{AD}$ & N/A & N/A & N/A & $\begin{array}{c}0.031^{* *} \\
(0.008)\end{array}$ & $\begin{array}{c}0.042 * * \\
(0.010)\end{array}$ & $\begin{array}{c}0.025 \\
(0.013)\end{array}$ \\
\hline HD & N/A & N/A & N/A & $\begin{array}{c}0.014 \\
(0.008)\end{array}$ & $\begin{array}{l}0.024^{*} \\
(0.011)\end{array}$ & $\begin{array}{c}0.006 \\
(0.012)\end{array}$ \\
\hline ADHD & $\begin{array}{c}0.023^{*} \\
(0.010)\end{array}$ & $\begin{array}{c}0.034 \\
(0.013) \\
\end{array}$ & $\begin{array}{c}0.014 \\
(0.015) \\
\end{array}$ & N/A & N/A & $\mathrm{N} / \mathrm{A}$ \\
\hline Depressed & $\begin{array}{c}0.029 \\
(0.015) \\
\end{array}$ & $\begin{array}{c}0.003 \\
(0.023) \\
\end{array}$ & $\begin{array}{c}0.046^{*} \\
(0.019) \\
\end{array}$ & $\begin{array}{c}0.029 \\
(0.015) \\
\end{array}$ & $\begin{array}{c}0.003 \\
(0.023) \\
\end{array}$ & $\begin{array}{l}0.046 * \\
(0.019) \\
\end{array}$ \\
\hline Obese & $\begin{array}{c}0.007 \\
(0.011)\end{array}$ & $\begin{array}{c}0.032 * \\
(0.016) \\
\end{array}$ & $\begin{array}{c}-0.020 \\
(0.016)\end{array}$ & $\begin{array}{c}0.009 \\
(0.011) \\
\end{array}$ & $\begin{array}{c}0.032 * \\
(0.016)\end{array}$ & $\begin{array}{c}-0.019 \\
(0.016)\end{array}$ \\
\hline
\end{tabular}

Note: Corrected standard errors in parentheses. Each cell contains information on the impact of smoking on a health outcome from a regression that also controls for all the factors listed in Table 7 , genetic markers, school and time period indicators. *, **, *** denote significance at $1 \%, 5 \%$, $10 \%$ level respectively. 